\title{
Board Dynamics over the Startup Life Cycle*
}

\author{
Michael Ewens ${ }^{\dagger} \quad$ Nadya Malenko
}

January 2022

\begin{abstract}
We explore the dynamics of venture capital (VC)-backed startup boards using novel data on director entry, exit, and characteristics. At formation, a typical board is entrepreneurcontrolled. Independent directors join the median board after the second financing, when control becomes shared, and hold a tie-breaking vote. Their presence is particularly likely when the potential for VC-entrepreneur conflicts is higher. At later stages, control switches to VCs and independent director characteristics change. These patterns are consistent with independent directors playing both a mediating and advising role over the startup life cycle, and thus representing another potential source of value-add to startup performance.
\end{abstract}

*The Internet Appendix is available here: https://osf.io/2hzun/. We are grateful to Rustam Abuzov, Audra Boone, Brian Broughman, Aycan Corum, Ofer Eldar, Rüdiger Fahlenbrach, Brian Gibbons, Erik Gordon, Will Gornall, Camille Hebert, Peter Iliev, Arthur Korteweg, Marie Lambert, Jonathan Macey, Andrey Malenko, Daniel Metzger, Salvatore Miglietta, Ramana Nanda, Oghenovo Obrimah, Uday Rajan, Sven Riethmueller, Merih Sevilir, Per Strömberg, Tarik Umar, Fei Xie, conference participants at the 2020 Private Equity Research Symposium, 2020 PCOB Workshop on Entrepreneurship and Finance, 14th Corporate Governance Conference at Drexel University, SFS Cavalcade North America 2021, 2021 Financial Intermediation Research Society, 2021 European Finance Association, 2022 American Finance Association, 2021 Midwest Finance Association, 2021 Northern Finance Association, 6th Advances in Venture Capital and Private Equity Research Online Workshop, 6th SDU Finance Workshop, Owners as Strategists Conference, 5th ENTFIN Conference, and seminar participants at multiple universities for helpful comments, and to Jiajie Xu, Shiyu Zhang, and Simran Khurana for research assistance. We thank the Private Capital Research Institute (PCRI) for access to the certificates of incorporation data.

${ }^{\dagger}$ California Institute of Technology and NBER. Email: mewens@caltech.edu.

${ }_{\ddagger}^{\ddagger}$ University of Michigan, CEPR, and ECGI. Email: nmalenko@umich.edu. 


\section{Introduction}

The board of directors has ultimate decision-making authority, so understanding corporate decisions requires documenting board composition and control. This is particularly true for venture capital (VC) backed startups, as their major shareholders - entrepreneurs and VCs - have different payoffs from decisions facing the board, are both active in the management and operations of the business, and their roles change substantially over the startup life cycle. While the literature has studied VC directors on startup boards (Lerner, 1995; Kaplan and Strömberg, 2003; Amornsiripanitch, Gompers, and Xuan, 2019), ${ }^{1}$ the two other director types entrepreneurs and independent directors - and how their roles on the board change over the firm's life, are yet to be explored. In particular, the distinct ownership structure of startups relative to public firms, with VCs being large and active blockholders, suggests that independent directors play more than the traditional monitoring role. Our goal in this paper is to explore the dynamics of board composition and control to understand the unique roles of independent directors over the startup life cycle.

Data limitations present challenges when answering these research questions because it has not yet been possible to identify all board members across many years and startups, determine their affiliations, and analyze when they join and exit the board. This limitation is particularly problematic for entrepreneur/executive directors and independent directors, who, as we document in this paper, are often missing or misclassified in the existing commercial databases. $^{2}$ Our first contribution is to fill this gap in startup board data by leveraging commercial databases, state and federal filings, and online resources. The resulting data provide both a view on the full board composition - director types and allocation of control - and its dynamic evolution over the firm's life cycle. Our second contribution is to use these data to highlight that startup board independent directors play a previously under-explored "mediation" role. That is, their presence helps mediate potential conflicts between VCs and entrepreneurs (Broughman, 2010, 2013; Blair, 2014). Moreover, the patterns of board composition over time

\footnotetext{
${ }^{1}$ Gorman and Sahlman (1989), Sahlman (1990), Kaplan and Strömberg (2004), Broughman (2010), and Venugopal and Yerramilli (2020) have also analyzed boards of VC-backed firms. We discuss our contributions to these papers in Section 1.1.

${ }^{2}$ For example, in almost half of observations, our data has more executive directors than VentureSource, leading to a different classification of board control in $49 \%$ of firm-years. VentureSource also often misclassifies investor directors as independent.
} 
and across firms are consistent with this mediation role being important in the early life of the startup and developing into an advisory role in later stages.

Building our panel database of startup boards requires merging three data sources. The first is Form D filings from SEC EDGAR, which list individual directors, indicate executive directors, and provide information on directors' start and end dates on the board. We merge these data with VentureSource, which provides information on investor-directors and some independent directors, but has limited information on executive directors and poor coverage of directors' start and end dates. The final piece is an extensive manual categorization of director types when there is any ambiguity about whether a director is independent, i.e., is neither the entrepreneur nor the representative of the investors. The resulting sample covers 7,780 startups over 2002-2017, which represents one of the largest samples in the literature in terms of both the set of startups and sample period. The distinctive feature of this data set is the ability to observe all director types and thus precisely measure the allocation of control between investors, executives, and independent directors over time.

We show that the average board size across a startup's life is 4.5, with approximately 2 seats held by VCs, 1.7 by executives, and 0.8 by independent directors. The dynamics of board composition reveal the shift of control over the life cycle. At first financing the average (median) board has 3.6 (3) members, and control is most frequently allocated to the entrepreneurs/executives. As the startup grows and raises capital, it adds both VC directors and independent directors, and at later stages of the life cycle, control is most typically allocated to VCs. Independent directors are widespread: they are present in about half of all firm-year observations, even though, unlike in public firms, their presence is not required by law. Moreover, independent directors play a key role in the evolution of board control over the life cycle. As the board transitions from entrepreneur to investor control, it typically goes through the stage that we call "shared control." At this stage, neither the VCs nor the entrepreneurs control the majority of seats on the board, so whenever these two parties disagree, independent directors have a tie-breaking vote and thus have substantial power over board decisions. Such shared control is particularly common after the second financing round, and the median firm at this stage has two executive directors, two VC directors, and one independent director. These patterns suggest important changes in directors' roles over the startup life cycle, which we explore in more depth. 
We also show substantial shifts in the allocation of board control over the last two decades. For example, the frequency of VC control after the second financing round fell from $60 \%$ for startups originated in 2003 to about $25 \%$ for startups originated in 2013, whereas the prevalence of entrepreneur control has almost doubled over these years. The fraction of boards with shared control has slightly increased but has overall remained stable.

To understand these board composition dynamics, we examine which factors determine the allocation of board control and the roles that independent directors play. First, independent directors could play an advisory role, providing advice and access to valuable resources and networks. However, this role alone cannot explain why these directors are so often given substantial voting power over the decisions: if the only role of independent directors were to provide advice and connections, there would be no need to give them a tie-breaking vote. ${ }^{3}$

We therefore investigate a different role of independent directors, which has been proposed in the law literature - the "mediation" role. ${ }^{4}$ We formalize this role and derive our key predictions building on Broughman $(2010,2013)$. The idea of the mediation role is that in an incompletecontracts setting (Grossman and Hart, 1986; Hart and Moore, 1990), independent directors can both ensure efficient decision-making by the board and, ex-ante, incentivize the VC and the entrepreneur to make capital and human capital investments, respectively.

Intuitively, suppose that at a certain point, the firm needs to make a decision that causes a disagreement between the VC and the entrepreneur. Such disagreements are likely to arise for decisions on subsequent rounds of financing, timing of exit, the sale of the firm, or CEO replacement, and particularly after negative shocks that require reorganization. If control over the board is given to either the $\mathrm{VC}$ or the entrepreneur, that party will want to pick the decision it prefers the most. However, it may be more efficient to instead take some "middle-ground" action, and this can be achieved by allocating a tie-breaking vote to an independent director, who, given his fiduciary duty (see Section 5.1), maximizes the value of the firm as a whole. Moreover, anticipating that the board will make efficient decisions, and not those that favor one party at the expense of the other, both the entrepreneur and the $\mathrm{VC}$ are more willing to make

\footnotetext{
${ }^{3}$ Moreover, the firm could establish an advisory board (as is frequently done in private firms) or add these individuals to the board as "board observers."

${ }^{4}$ Statements by industry practitioners confirm that this role of independent directors is viewed as important. For example, venture capitalists Brad Feld and Jason Mendelson write: "... these outsiders can mediate issues that arise between the company and investor-elected board members" (Feld and Mendelson, 2019).
} 
ex-ante investments. Put differently, allocating the tie-breaking vote to independent directors offers a commitment to both parties to refrain from opportunistic behavior in the future. ${ }^{5}$

Whether such shared control emerges or not depends on the relative importance of each parties' ex-ante investments and their outside opportunities. When either the VC's or entrepreneur's relative bargaining power is particularly high (because their required investment is large and they have high outside opportunities), that party gets full board control. However, when neither parties' bargaining power is high, independent directors are given a tie-breaking vote, i.e., shared control emerges.

This logic leads to our key predictions. First, within the startup life cycle, as the amount of capital contributed by the VC investors increases whereas the relative importance of the entrepreneur's human capital investment declines (e.g., Rajan, 2012; Kaplan, Sensoy, and Strömberg, 2009), control over the board should shift from entrepreneur control at early stages of financing, to shared control at intermediate stages, and to VC control at later stages. Second, across firms, as the VC's bargaining power relative to the entrepreneur increases, we expect the allocation of control to move from entrepreneur control, to shared control, and then to VC control. Finally, a negative shock to the required amount of the VC's capital investment should shift board control from VCs to entrepreneurs.

We show that these predictions are consistent with the observed patterns in the data. Within the life cycle, the allocation of control shifts from the entrepreneur $(47 \%$ of firms at the first financing), to shared control (36\% of firms at the second financing), and then to VC control (62\% of firms by the fourth financing). Conditional on a change in board control from one year to the next, entrepreneur control is $71 \%$ likely to switch to shared control, and shared control is $85 \%$ likely to switch to VC control. These patterns are robust to controlling for the founder's equity stake, and thus are not driven by increased VC ownership over the life cycle.

To test the second prediction in the cross-section of firms, we proxy for the VC's bargaining power relative to the entrepreneur in two ways. The first measure is at the industry level: we consider the equity stake obtained by VCs for a given amount of contributed capital (i.e., the ratio of capital invested to post-money valuation), and take its average across all financings within an industry in the previous year. A higher industry-average VC equity stake corresponds

\footnotetext{
${ }^{5}$ See Fried and Ganor (2006), Atanasov, Ivanov, and Litvak (2012), and Eldar, Grennan, and Waldock (2020) for discussions of opportunistic behavior by VCs, and In re Trados and In re Nine Systems for case studies.
} 
to higher industry-level VC bargaining power in negotiations over firms' valuations. Our second proxy is a measure of dry powder at the geographical region level, which is calculated as the sum of all capital raised by VC funds in this region in the past, net of the sum of all capital invested into startups in this region in the past. In years when dry powder is low, VC bargaining power is high (because the supply of capital is scarce), and vice versa.

Consistent with the second prediction, there is a monotonic negative relation between entrepreneur control over the board and both proxies for VC bargaining power. Likewise, there is a monotonic positive relation between $\mathrm{VC}$ control and both proxies. Both the within-life cycle and the cross-sectional results are robust to a more conservative definition of independent directors, which treats directors with prior professional ties with the $\mathrm{VC}$ or the entrepreneur as being affiliated with that party, and only considers unconnected directors as independent.

To test the third prediction, we exploit a negative shock to the relative importance of VC capital brought by the introduction of Amazon's Web Services (AWS) in 2006. By removing the need for large upfront investments in hardware, this technological development decreased the cost of starting new startups and, accordingly, the amount of capital contributed by the VCs in early stages. We follow Ewens, Nanda, and Rhodes-Kropf (2018) and use a difference-indifference design, defining industry segments as treated if they were particularly affected by the introduction of cloud computing. We find that relative to control firms, treated firms experienced a significant reduction in the likelihood of VC control over the board and a significant increase in the likelihood of entrepreneur control following the shock. The above discussed time-series trends in board control are thus at least partly driven by the AWS shock. However, the fact that shared control is still widespread suggests that the mediation role of independent directors continues to be important.

If independent directors are invited to mediate future conflicts between VCs and entrepreneurs, their presence should be more likely when the ex-ante potential for such conflicts is higher. One decision that involves a clear conflict between these two parties is about whether to replace the founder, and the ex-ante likelihood of such a conflict is higher if the VC has a reputation for replacing founders in the past. We therefore identify VC investors with a particularly high propensity of replacing the CEO in their past portfolio firms. Consistent with the mediation hypothesis, we show that if the first financing round involves at least one such VC, there is a $19 \%$ higher likelihood of an independent director being on the board in 
this round and having a tie-breaking role. These results highlight that unlike in public firms, where independent directors are added to protect investors from the opportunistic behavior of executives (monitoring), independent directors on startup boards are added to protect both, executives and investors, from the opportunistic behavior of the other party (mediation).

In addition to mediation, independent directors could be playing an advisory role and helping the professionalization of the startup, particularly in its later stages. We find that director characteristics change over the life cycle in a manner suggesting their changing role on the board. Independent directors who join in later stages have held more executive-level positions in the past and are more likely to have served on a public board, consistent with their advisory role becoming relatively more important. On the other hand, independent directors joining in early stages are more likely to have founder experience, which makes them more predisposed towards entrepreneurs and could allow them to be more effective mediators despite the pressure to be VC-friendly. In addition, directors joining early on, during the entrepreneur and shared control stages, are more likely to be unconnected to either VCs or entrepreneurs through their past professional experience, consistent with the mediation role requiring directors to be truly independent and impartial.

\subsection{Related literature}

Our paper contributes to the large literature on corporate boards (see Adams, Hermalin, and Weisbach (2010) for a comprehensive survey). Given the data limitations, most of this literature focuses on boards of publicly listed firms. Our contribution to the literature on private firm boards is to analyze the full composition and dynamic evolution of boards for a comprehensive sample of VC-backed startups. In particular, the combination of Form D filings, VentureSource, and manual data collection allows us to identify board members beyond the VC directors and capture directors' start and end dates. These additions fill the gaps in board coverage common to commercial datasets such as VentureSource (incomplete executive director coverage and missing dates), Crunchbase (missing directors and dates), and Pitchbook (missing directors and incomplete coverage of start dates). The advantage of filling these gaps is our ability to determine how control over the board and the voting power given to independent directors change over the life cycle, which are the key questions we study in the paper. 
Our interest in the dynamics of board control and unique roles of independent directors distinguish our paper from most other studies of VC-backed boards, which mostly focus on VC directors, examining what factors lead VCs to take board seats and how this impacts outcomes. Lerner (1995) is the first comprehensive study of VC board activity, which studies VC directors' role in $\mathrm{CEO}$ turnover and how $\mathrm{VC}$ board positions relate to their geographic distance to the firm. Amornsiripanitch, Gompers, and Xuan (2019) analyze a large sample of startup boards and show that prior VC-founder relationships and lead investor status are important predictors of $\mathrm{VC}$ board membership and that the presence of $\mathrm{VC}$ directors is associated with recruiting from their networks and relationship-based acquisitions. Venugopal and Yerramilli (2020) study boards in the Series A round and examine how non-executive directors' appointment is related to their experience and ties with founders and investors, as well as to subsequent outcomes. These two papers rely, respectively, on VentureSource and Crunchbase, which we believe are insufficient to document the full composition, control, and dynamics of the board (see Section A3.4 of the Internet Appendix for details $\left.{ }^{6}\right) .{ }^{7}$ Researchers have also studied the role of board seats in contracts and general investor control rights. Kaplan and Strömberg (2003) examine a sample of VC contracts and find that most separately define board seats, cash flow rights, and control rights. They show that while state-contingent provisions for cash flow and voting rights are common, board rights are typically not state-contingent. ${ }^{8}$ The role of independent directors is not a focus of their study. Kaplan and Strömberg (2004) find that two measures of risks faced by startups - internal and external - are related to investor board membership, and that $\mathrm{VC}$ board control is predictive of interventions such as $\mathrm{CEO}$ replacement.

In the context of public firms, the literature emphasizes two roles of independent directors: monitoring and advising. ${ }^{9}$ While we find evidence consistent with the advisory role of independent directors, our focus is on their mediation role and on the transition from mediation

\footnotetext{
${ }^{6}$ The Internet Appendix is available here: https://osf.io/2hzun/.

${ }^{7}$ Montag (2021) analyzes the role of non-executive directors' expertise in Swedish limited liability companies. Cornelli and Karakaş (2015) analyze boards in LBOs backed by private equity funds.

${ }^{8}$ Out of 213 contracts in their sample, only $0.5 \%$ (one contract) features board control that is contingent on financial performance and no contract features board control contingent on non-financial performance. While $19 \%$ of contracts feature dividend/redemption default contingencies, these refer to borderline financial milestones and are rare.

${ }^{9}$ See, e.g., Weisbach (1988), Yermack (1996), Hermalin and Weisbach (1998), and Fich and Shivdasani (2006) for the monitoring role and Adams and Ferreira (2007), Coles, Daniel, and Naveen (2008), Field, Lowry, and Mkrtchyan (2013), and Harford and Schonlau (2013) for the advisory role.
} 
to advising over the life cycle. We also highlight the distinction between the monitoring and mediation roles: monitoring is important in pubic firms with dispersed ownership, whereas mediation is important in startups, where ownership is concentrated and both VCs and entrepreneurs are large shareholders with board representation. These differences in ownership structures and in the roles of independent directors can explain the differences in the dynamics of startup boards and public boards (e.g., Denis and Sarin, 1999; Boone, Field, Karpoff, and Raheja, 2007; Graham, Kim, and Leary, 2020). ${ }^{10}$ Our paper is also related to studies of boards of VC-backed firms after their IPOs. Field, Lowry, and Mkrtchyan (2013) and Iliev and Lowry (2020) show that VCs continue to play an active role on boards of their portfolio firms after the IPO, and Baker and Gompers (2003) and Hochberg (2012) find that at the time of the IPO, VC-backed firms have a higher fraction of independent directors, hypothesizing that VCs bring independent outsiders to monitor the manager after the IPO.

The idea of the mediation role goes back to Blair and Stout (2001), who view directors "as 'mediating hierarchs' ... charged with the task of balancing the sometimes-conflicting claims and interests of the many different groups." Blair (2014) contrasts the monitoring and mediation roles and highlights the importance of mediation in VC-backed firms. Broughman (2010, 2013) presents a theory showing how independent directors can mediate between VCs and entrepreneurs, which we build on in Section 5, and provides descriptive statistics on 54 startups. While the mediation role has received attention in the law literature, it has been discussed less in the finance literature. Burkart, Miglietta, and Ostergaard (2021) analyze Norwegian public firms at the turn of the $20^{\text {th }}$ century and show that firms with large, heterogeneous shareholder bases were more likely to set up a board, hypothesizing that boards both mediated among shareholders and monitored managers. Villalonga, Trujillo, Guzmán, and Cáceres (2019) study closely held Colombian firms and find that boards are more likely to arise when the number of shareholders is larger, consistent with the need for a board to mitigate collective action problems and conflicts. These papers view the entire board as a mediator between shareholders,

\footnotetext{
${ }^{10}$ For example, we document that the key source of board size growth as the startup raises more capital is the addition of investor-directors (e.g., Figure 1), whereas Boone et al. (2007) show that over ten years after the IPO, the public board grows primarily due to the addition of independent directors (who represent investors in public firms). Another interesting difference is the dynamics of CEO power over the board: we show that executives in startups lose board control over the life cycle, whereas Graham, Kim, and Leary (2020) show that as CEO tenure increases, the CEO gets more power over the board (board independence declines and CEO-chair duality becomes more likely); similarly, Boone et al. (2007) find a negative relation between board independence and CEO tenure.
} 
whereas our focus is on independent directors mediating between other directors on the board.

\section{The startup board}

Through surveys and small sample data collection, we have a broad understanding of what VC-backed boards do. A recent survey of venture capitalists by Gompers, Gornall, Kaplan, and Strebulaev (2020) shows that a typical VC considers board control an important part of deal negotiation. The board itself has many responsibilities, summarized in the 2007 white paper by a group of VC industry experts as "serving as fiduciaries for all shareholders; hiring, evaluating, and firing the CEO and approving officer selection; ... reviewing and confirming basic company objectives and business strategy; ... approving equity incentives and establishing executive compensation; [and] overseeing regulatory and legal compliance" (p.12). ${ }^{11}$

Moreover, Fried and Ganor (2006) emphasize that "startup boards - unlike public company boards - are frequently and intimately involved in strategic decision-making and personnel issues" and note that board control gives the controlling party the ability to "initiate fundamental transactions such as mergers, IPOs, and liquidations" (p.987). All these decisions can give rise to potential disagreements between VCs and entrepreneurs, and the allocation of board control is key to how these disagreements are resolved.

In addition to board seats, VCs may exercise contractual control through protective provisions, which give them veto rights. In Section A5 of the Internet Appendix, we discuss the data on protective provisions and why we believe that our results are not affected by their presence.

\section{Data}

We aim to build a database of board composition that addresses the limitations of commercial and public data sources on VC-backed boards. For example, in the process of building our data we learned that commercial databases used in the literature do not track executive directors, miscategorize directors' types, and typically lack directors' start and end dates. Similarly, public data sources (i.e., Form D filings) can only show a partial picture of the board on their

\footnotetext{
${ }^{11}$ See "A Simple Guide to the Basic Responsibilities of VC-backed Company Directors," issued by the Working Group on Directory Accountability and Board Effectiveness.
} 
own. The combination of the two - along with other data collection - provides the best view of the board's composition and control. In the Internet Appendix, we discuss in more depth the strengths and limitations of various databases of startup boards, our data collection process (summarized in Figure A1), Form D filing requirements, and other institutional details.

We are interested in board composition of U.S.-based VC-backed startups financed from 2002 to 2017. Our key source of data are regulatory Form D filings combined with VentureSource. Identifying the full board, especially executive directors, demands that we impose several sample filters on the set of startups in VentureSource to minimize measurement error. First, to ensure that there are some shareholders who could have board rights, we require the startup to raise equity financing (e.g., not convertible notes or straight debt) at least once during 2002-2017. Second, for at least one financing during the sample period, equity capital has to be provided by at least one traditional U.S.-headquartered VC. ${ }^{12}$ Third, to ensure that we see the board over the entire life cycle starting at first VC financing, we require that the startup's first VC financing in VentureSource is accompanied (within 15 days) by the filing of a Form D. A lack of a filing may be because the startup raised capital in only one state or simply failed to comply with the regulation. Fourth, the startup's Form Ds must report at least one executive director by the end of the sample period. This condition is important because VentureSource has limited information on executive directors. We start tracking startups after they raise their first VC financing (as reported in VentureSource). With the VentureSource sample defined this way, we search for these startups on the SEC EDGAR site, i.e., find their CIK identifiers, to extract their Form D filings.

Form D filings are exemption requests made by startups raising private capital. Regulations require that Form Ds are filed within 15 days of the first sale of securities. They contain a list of the firm's directors, and for each director, indicate whether the director is an executive

\footnotetext{
${ }^{12}$ Most commercial data providers define a traditional VC as a firm that manages limited life funds that raise capital from institutional investors; those funds have a fee and carry compensation scheme for general partners and a stated objective of investing in high-growth private firms. Investors that do not classify as traditional VCs include corporate VCs, angels, individuals, and large private equity investors (e.g., buyout or growth equity investors). Startups in VentureSource that raised capital only from these other investors are thus not in our sample. However, if a startup raised capital from at least one traditional U.S.-based VC, then we classify all its directors affiliated with investors (including these other types) as investor-directors. Finally, to avoid capturing startups that are mis-classified as VC-backed or that are relatively developed by the time they are tracked by VentureSource, we also exclude startups whose first observed financing is a public investment in private equity, a restart round, a secondary transaction, a later-stage financing, or a grant from a private organization.
} 
(see Figures A2 and A3 in the Internet Appendix). For 2002-2009, these filings are available in pdf form. Individual names and titles, such as executive or director, were extracted with a combination of pdf processing and manual data collection. Filings posted after 2008 are in machine-readable format (XML). The resulting list of directors is next merged with VentureSource. VentureSource provides information on investor-directors and some independent directors (called "Outsiders"); it also has information on partners at the investing VC firms and the startup's executives, whereas Form D data are crucial for identifying executive directors. In particular, we classify as "executive directors" those who have two boxes checked on the Form D ("Director" and "Executive Officer"). For other directors on the Form D, we first rely on VentureSource to identify their type: We use the list of investors in the startup and their partners as well as investor-directors from VentureSource to identify the non-executive directors on the Form D as investor-directors. Part of the remainder directors on the Form D merged with VentureSource's "Outsiders", and we then classify them as "independent." For all the remaining directors, we perform a manual check using CrunchBase, LinkedIn, and Google, which allows us to further classify those directors into investors (including angels), executives, and independent.

The combination of these databases thus provides information on executive directors and flags directors in Form Ds as one of three types: executives, who we refer to interchangeably as entrepreneurs; investors (who we call "VC directors"); or independent. The Form Ds are themselves an imperfect source of board data. There are cases where VentureSource reports investor-directors or independent directors not found in a contemporaneous Form D. These are likely the cases where the election of the director happened after the Form D filing deadline, so we add directors only available in VentureSource to our sample.

The Form D data also provide a crucial piece of information most often missing in commercial data providers: director start and end dates. We assign the date of the first Form D that mentions a director as the director's start date. In cases where a director's start date is also available in VentureSource, we use the minimum between the Form D-based and VentureSource start dates. ${ }^{13}$ We use Pitchbook to provide additional information on start dates in cases when

\footnotetext{
${ }^{13}$ To get start dates for directors only available in VentureSource, we use a combination of reported start dates in VentureSource and dates when the VentureSource research team updated the board data. During most of our sample period, VentureSource contacted a startup or its investors twice a year. If a start date is missing, but the "last update date" field is known and varies across directors (if they are all the same, VentureSource
} 
we lack a start date after combining these data. As for a director's end date, it is set either to six months prior to the first Form D in which the director is no longer listed, ${ }^{14}$ or to the date of exit (e.g., IPO, failure, or acquisition), whichever is earlier. Startups without exits by the end of the sample period are tracked for two years after their last VC financing event, to ensure that we do not impose stale board data from still-private startups.

The last step is a transformation of the data. The merge of VentureSource and the Form D results in a unit of observation at the financing event. Using the date of first financing and either the eventual exit or the end of the sample period, we create a startup-year panel. Board composition for years with more than one financing is set based on the last financing of that year, while board composition in years without financings is imputed from the previous year. ${ }^{15}$

The final data set provides the evolution of the full board of directors, from first $\mathrm{VC}$ financing to exit, for a sample of 7,780 startups.

Form D filers and data accuracy. Table 1 reports the characteristics of firms in our sample and compares them to firms in VentureSource that satisfied the main sample rules (raised equity financing by at least one traditional U.S.-based VC during our sample period), but either never filed a Form D (62\% of that sample) or filed it at some point but did not satisfy other sample rules (e.g., because there was a VC financing before the first Form D filing). Firms in our sample are more likely to have a first round Series A because seed financings are often raised from smaller, non-traditional VCs, who are less likely to comply with Form D regulations. Sample firms are also more likely to be headquartered outside CA: startups outside CA often need to raise capital out of state and as a result, cannot satisfy the exemptions to avoid form D filing. Next, driven by some backfill in Form D filings by firms going public, sample firms are more likely to go public and in turn, have more financings. Despite these differences, we believe

said it is most likely late backfill), then we use this updated date.

${ }^{14}$ If the previous Form D filing is less than six months from the current filing, then the end date is set to the halfway point between the two filings.

${ }^{15}$ The rights to elect board members are almost always negotiated at the same time as financing events (see the discussion of certificates of incorporation in Section A3.4 of the Online Appendix), but the actual election of board members may sometimes occur later. In this case, Form D may be filed before the agreed upon board seat is filled. However, we do not think this happens often, or that it introduces any bias. First, as noted above, if the director is also available in VentureSource, we use the earliest of the two start dates; moreover, the VentureSource date rarely disagrees with the Form D-based date by more than 4-6 months. Second, we observe such a director in the subsequent Form D, and since most startups raise capital every 1.6 years, the lag is about a year and is uniform over the life cycle. 
that our sample of firms is generally representative of the VC universe during the sample period.

In Section A3 of the Internet Appendix, we provide a comprehensive analysis to alleviate potential concerns about our use of Form Ds and compare them to other data sources. First, we ask whether startups with at least one Form D filing are different from the average VC-backed startup. The analysis suggests that Form D filers are a bit older, are less likely to be based in $\mathrm{CA}$, and raise more capital over their lives, and we explore the sources of these differences based on the existing disclosure regulations. Next, we investigate whether these differences manifest themselves in board characteristics. Using a small, nearly-comprehensive sample of board data for non-Form D filers in one state (MA), we find that boards of Form D filers are larger but exhibit no major differences in composition or dynamics. Finally, we examine whether Form Ds provide accurate data on directors. We compare Form Ds and annual reports for a small sample of firms from MA and show that in the vast majority of cases, there is agreement between the two, and any disagreements are driven by idiosyncratic features of the startup. We also analyze a small sample of certificates of incorporation and find no evidence that Form D data has major gaps in coverage. We conclude that board data collected from a combination of Form D filings and commercial databases has no major bias in the cross-section or time series.

Allocation of control. We call a board "VC-controlled" if VC directors hold strictly more than $50 \%$ of seats, or if they hold exactly $50 \%$ of seats and executives hold strictly less (i.e., the remaining $50 \%$ of seats are split between executives and independent directors). ${ }^{16}$ We call a board "entrepreneur-controlled" if executives hold strictly more than $50 \%$ of seats, or if they hold exactly 50\% and VCs hold strictly less. In addition, our sample includes some startups whose boards are initially empty but add directors in subsequent rounds of financing. We define such boards at their initial, empty, stage as entrepreneur-controlled because the absence of a board is likely to mean that the entrepreneur has control over the decisions. We refer to the remaining boards as having "shared control." In a typical board in this category, both VCs and entrepreneurs hold strictly less than $50 \%$ of seats, while the remaining seats are held by independent directors, who thus have a tie-breaking vote when the two parties disagree. ${ }^{17}$

\footnotetext{
${ }^{16}$ In this second case, the most unfavorable situation for the $\mathrm{VC}$ is one where independent directors always side with executives, resulting in deadlock. In all other scenarios, the VC can implement its preferred decision.

${ }^{17}$ Some boards with shared control feature exactly $50 \%$ of seats held by both VCs and executives and do not have independent directors; we call them "deadlock boards" (e.g., Donaldson, Malenko, and Piacentino, 2020). Our results are robust to excluding deadlock boards (see Tables A10 and A11 in the Internet Appendix).
} 


\section{Startup board over the life cycle}

This section describes the basic patterns in the board data for firms in our sample. Table 2 presents summary statistics for the panel data of board composition. Because Form Ds are only filed during new financing rounds, we observe board composition only in years when new financings are raised. For each year without a financing event, we impute board data from the previous financing event. Accordingly, Panel A reports all firm-year observations, while Panel $\mathrm{B}$ only reports the subset of firm-years in which the firm raised at least one equity financing.

According to Panel B, the average board size across a firm's life is 4.5. About 2 of the directors are VCs, while 1.7 and 0.8 of the seats are held by executives and independent directors, respectively. This composition corresponds to an average of 40\%, 45\%, and $15 \%$ of seats controlled by VCs, executives, and independent directors. Independent directors are very common: they are present in $49 \%$ of firm-financing year observations.

Figure 1 reports board seat counts by firm age, where age zero corresponds to the year when the startup first raises VC equity financing. On average, startup boards start with fewer VC investors than executives. However, the number of VC directors grows over time, whereas the number of executives does not. The number of independent directors also grows (from zero to one for the median firm), and the median firm adds an independent director around year 3 . These dynamics are not driven by survivorship: restricting the sample to startups that survived for at least $N$ years has no impact on the patterns (see Figure A12 of the Internet Appendix).

Figure 2 reports the fraction of the board composed by each type of director by firm age. Consistent with the patterns in Figure 1, the fraction of executives on the board decreases (from 0.55 in early years to 0.30 in later years), and the fraction of investor-directors increases with age. The median fraction of seats occupied by independent directors first increases but stabilizes at about 0.17 after the first two years. These patterns are consistent with entrepreneurs having control over the board in early stages but losing it over time, and VCs gaining control. In many years, however, neither the executives nor the VC directors have a majority of the seats, suggesting that independent directors have playing a tie-breaking vote.

To investigate these control patterns formally, we present more detailed statistics about the composition of a typical board at each round of financing in Table 3. In the first round, entrepreneurs control about $56 \%$ of seats in an average board, and the median board has two 
entrepreneurs and one VC director. In the second round, the firm adds another VC director, but simultaneously also adds an independent director. The most common arrangement is thus shared control: the median board has two entrepreneurs, two investors, and one independent director to break the tie in case of disagreement, and the average percentages of entrepreneur and VC board seats are $43 \%$ and $41 \%$ respectively. Over subsequent rounds of financing, the number and fraction of VC directors gradually increase, and by the fourth financing round, the average firm has $53 \%$ of board seats controlled by investors.

Figure 3 uses the definitions of board control introduced in Section 3 to show the evolution of control over the life cycle. Entrepreneur control is most common after the first financing round: $48 \%$ of startups are controlled by entrepreneurs, as opposed to $20 \%$ by VCs and $32 \%$ with shared control. As the firm raises additional financing, entrepreneur control declines, whereas shared control and VC control become more prevalent. Shared control is overall very common: across all stages of the life cycle, it is observed in about a third of startups, and it is the most common arrangement in intermediate stages. Finally, VC control is most common in later stages: it is observed in $52 \%$ and $63 \%$ of firms in the third and fourth round, respectively.

We next ask whether the allocation of control has changed over our sample period. The left panel of Figure 4 presents the time series summary of VC board control for age cohorts. The $x$-axis is the year a startup raises its first round of VC equity, and each time series presents the fraction of that cohort that had a VC-controlled board in round one, two, and three. (The $x$-axis ends in 2013 because the third financing round for the 2013 cohort corresponds to the end of our sample period, i.e., 2017.) The figure reveals a significant decline in the probability of VC control over the board. The youngest firms have experienced the largest decline: firstand second-round boards have roughly half the probability of VC control since 2012 than those in the early 2000s. The middle and right panel of Figure 4 present the same time series analysis, but for the fraction of firms with entrepreneur and shared control, respectively. Together, these figures show a shift in board control from VC investors to entrepreneurs. In contrast, the fraction of firms with shared control has remained relatively stable or even slightly increased..$^{18}$

\footnotetext{
${ }^{18}$ In Figures A8 and A9 of the Internet Appendix, we show that similar trends are observed within the IT and healthcare industry separately, and in Figure A10 of the Internet Appendix, we explore the trends in additional board characteristics, such as board size and the presence of independent directors.
} 
Summary. Overall, the data reveal the following patterns. First, over the firm's life cycle, entrepreneurs lose control over the board, and VC investors gain control. Second, independent directors are playing a key role in this transition, with shared control being particularly common in the second financing round. Moreover, an independent director is typically added together with a new VC director, as if to prevent a deadlock situation or a switch of control to VCs that would have occurred otherwise. Finally, over the last decades, control has shifted from VCs to entrepreneurs, but the role of independent directors has remained important.

To understand these patterns, we next discuss and formalize the idea of the mediation role, which gives rise to our key predictions. We test these predictions in Section 6 .

\section{Mediation role of independent directors}

The idea of the mediation role is that independent directors with a tie-breaking vote can mediate conflicts between entrepreneurs and VCs. This role of independent directors is consistent with industry practitioners' views. Reid Hoffman, the co-founder of LinkedIn and a venture capitalist, writes: "One of the really important roles for independents is to serve as a catalyst and bridge between management and investors." He describes his own experience as an independent director in building a compromise in the decision on equity grants, which he views as an example of conflicts "which an independent board member can help mediate" and concludes: "It's the independent director's job to provide this kind of balanced perspective on conflicts." 19 Similarly, the NVCA (the lobbying group for the VC industry) provides "model documents" such as investor rights agreements, certificates of incorporation, and voting agreements, and in the latter, they discuss that in the eyes of the court, independent directors can lessen the need for alternative contractual terms that deal with exit decision conflicts.

\subsection{Are independent directors truly independent?}

The mediation role requires that independent directors do not represent the sole interests of VCs or entrepreneurs, so an important question is whether they are truly independent. For example, due to their extensive networks, VCs may exercise undue influence over director appointments,

\footnotetext{
${ }^{19}$ See https://greylock.com/greymatter/building-a-great-startup-board-pt-2. See also footnote 4 above.
} 
which could tilt directors towards favoring VCs. However, based on our examination of case law, conversations with practitioners, and analysis of the data, we believe that in most cases, we can view independent directors as not being beholden to either party.

First, we point out that such directors are jointly appointed to the board by mutual consent of entrepreneurs and VCs. ${ }^{20}$ Second, directors have fiduciary duties to the corporation and its stockholders as a whole. In the context of startups, this effectively implies fiduciary duties to common stockholders because case law (e.g., In re Trados and In re Nine Systems) views the interests of preferred stockholders as being protected by their contractual rights. ${ }^{21}$ Moreover, as these high-profile court decisions and our discussions with practitioners and lawyers made clear, for directors to avoid the risk of personal liability, not only the board should not be dominated by VCs, but also independent directors should be truly "disinterested." 22 Consistent with this view, the law firm Fenwick \& West advises its clients: "Consider how independent "independent directors" truly are ... boards needs to carefully examine whether "independent" board members may be characterized as being beholden to the VCs that control the board by virtue of their previous business relationships, history, affiliations and other contacts." 23

Third, our conversations with practitioners revealed that independent directors are typically compensated with common, and not preferred, stock, which further aligns their interests with

\footnotetext{
${ }^{20}$ For example, according to the NVCA model voting agreement, an independent director is an "individual not otherwise an Affiliate of the Company or of any Investor who is [mutually acceptable to (i) the holders of a majority of the Shares held by ... officers, employees or consultants; and (ii) the holders of a majority of the Shares held by the Investors." This is different from either VC-directors or executive directors, who are designated by the preferred (common) shareholders, rather than jointly. See https://nvca.org/recommends/ nvca-2020-voting-agreement-2/ for the language describing the elections of each type of directors.

${ }^{21}$ For example, according to In re Trados, "it will be the duty of the board ... to prefer the interests of the common stock ... to the interests created by the special rights, preferences, etc. ... of preferred stock. ... in circumstances where the interests of the common stockholders diverge from those of the preferred stockholders, it is possible that a director could breach her duty by improperly favoring the interests of the preferred stockholders over those of the common stockholders." See Boschner and Simmerman (2016) for a more detailed discussion. This, of course, does not mean that independent directors can favor entrepreneurs at the expense of the corporation and other stockholders, as this would violate their fiduciary duties as well.

${ }^{22}$ This is because when the majority of directors are truly "disinterested," the "business judgment rule" protects directors from personal liability for allegedly poor decisions. However, if the majority of directors are not disinterested, the court uses a much more stringent "entire fairness standard," making personal liability significantly more likely. In both In re Trados and In re Nine Systems, the court applied entire fairness and concluded that the board's decision-making process had been grossly unfair.

${ }^{23}$ See Cogen et al. (2013). A similar view has been expressed by Fred Wilson, a well-known VC and blogger: "Founders and investors can and do think about what is best for the Company, but they also think about what is best for them. An independent director can and should represent the Company in Board discussions." See "Independent Director Compensation," AVC Blog, Aug 5, 2020.
} 
those of the corporation, rather than the VCs. Nevertheless, another potential concern could be directors' labor market incentives: they may want to favor VCs and develop a reputation for being VC-friendly in order to be invited to boards of other VC-backed startups in the future. However, Table 9 (variable "Total board seats") shows that a typical independent director does not serve in this role more than once: the average (75th percentile) number of board seats over a director's career is 1.16 (1), suggesting that such labor market incentives are unlikely.

To alleviate any remaining concerns about director independence, in Section 8, we analyze the data on past connections between directors and show that all our results remain robust if we use a more conservative definition of independence that accounts for connections. ${ }^{24}$

\subsection{Modeling the mediation role}

To formalize the mediation role and derive our key predictions, we build on Broughman (2010, 2013), who considers an incomplete-contracts setting similar to Aghion and Bolton (1992).

There is a risk-neutral entrepreneur (E) and a risk-neutral venture capitalist (VC). The entrepreneur is cash-constrained, while the $\mathrm{VC}$ is not. At time $t_{0}$, the $\mathrm{VC}$ decides whether to finance the firm, and the entrepreneur decides whether to contribute his human capital. Both parties receive their outside options, $I^{V C}$ and $I^{E}$, if these ex-ante investments are not made.

If both parties make investments, then at time $t_{1}$, the firm can choose between one of three possible actions $\{1,2,3\}$. For example, these actions could represent the timing of the IPO (early, intermediate, and late) or the terms of the next round of financing. The payoffs for the entrepreneur and $\mathrm{VC}$ from Action $i$ are given by $V_{i}^{E}$ and $V_{i}^{V C}$, respectively, and there is no discounting. For simplicity, we assume that these payoffs are non-transferable. ${ }^{25}$

Suppose that the VC prefers Action 1 the most $\left(V_{i}^{V C}\right.$ is the highest for $\left.i=1\right)$, whereas the entrepreneur prefers Action $3\left(V_{i}^{E}\right.$ is the highest for $\left.i=3\right)$. However, Action 2 is efficient in that it maximizes their combined payoff, $V_{i}^{V C}+V_{i}^{E}$. Together, these three assumptions imply

\footnotetext{
${ }^{24} \mathrm{~A}$ natural question is whether directors who are truly independent are sufficiently informed to play their mediation role effectively. We believe the answer is yes: given their tie-breaking vote upon a disagreement, both executives and investor-directors have strong incentives to reveal information to them to make their case, so the independent directors will be informed about the pros and cons of each option. This is another important difference of startup boards from public boards: independent directors on public boards receive information primarily from the CEO (e.g., Adams and Ferreira, 2007).

${ }^{25} \mathrm{~A}$ standard assumption in the literature is that part of the payoffs is non-transferable (e.g., private benefits) and part is transferable (security benefits). The model can be extended to capture this more general assumption at the cost of additional complexity but without changing the intuition (see Broughman, 2013).
} 
that $V_{3}^{E}>V_{2}^{E}>V_{1}^{E}$ and $V_{1}^{V C}>V_{2}^{V C}>V_{3}^{V C}$.

Contracts are incomplete, and the parties cannot contract on actions. Instead, the decision is made by the board, which can be controlled in three different ways. In an entrepreneurcontrolled (VC-controlled) board, the entrepreneur (VC investor) has full authority to choose the action. In a board with shared control, neither the VC nor the entrepreneur have authority. Instead, there is an independent director, who effectively acts as a mediator: the VC and the entrepreneur each suggest an action, and the independent director chooses between the two proposed actions. The independent director maximizes the parties' joint payoff, $V_{i}^{E}+V_{i}^{V C}$.

We next consider the board's choice over the actions and the ex-ante investment decisions by both parties under the three types of allocation of control.

Entrepreneur control. If the entrepreneur has control, he wants to choose Action 3. However, since the $\mathrm{VC}$ investor is not cash constrained, there is a possibility of renegotiation: we assume that the VC can make a take-it-or-leave-it offer to the entrepreneur to convince him to take a different action. Then, the VC will offer the entrepreneur just enough cash to induce the efficient Action 2 (inducing the entrepreneur to take the VC's preferred Action 3 would be too costly). That is, the VC makes the entrepreneur indifferent between Actions 2 and 3 by offering $V_{3}^{E}-V_{2}^{E}$. Thus, Action 2 is taken, and the expected payoffs of the entrepreneur and the $\mathrm{VC}$ are, respectively, $V_{3}^{E}$ and $V_{2}^{V C}-\left(V_{3}^{E}-V_{2}^{E}\right)$. In order for this allocation of control to ensure ex-ante investments of both parties, the following constraints need to be satisfied:

$$
\begin{aligned}
V_{3}^{E} & \geq I^{E}, \\
V_{2}^{V C}-\left(V_{3}^{E}-V_{2}^{E}\right) & \geq I^{V C} .
\end{aligned}
$$

VC control. Under VC control, the VC wants to choose Action 1. Because the entrepreneur is cash constrained and the payoffs are non-transferable, there is no renegotiation, so Action 1 is taken. The parties are willing to make ex-ante investments if and only if ${ }^{26}$

$$
\begin{aligned}
V_{1}^{E} & \geq I^{E}, \\
V_{1}^{V C} & \geq I^{V C} .
\end{aligned}
$$

\footnotetext{
${ }^{26}$ Note that if $V_{1}^{E}<I^{E}$, it is technically possible for the VC to offer cash to the entrepreneur at time $t_{0}$ to convince him to participate. For simplicity, we shut down this option, motivating it by the lack of commitment power by the entrepreneur: if his human capital investment is non-verifiable, he could take cash at time $t_{0}$ and then still not invest his human capital and exercise his outside option, so such transfers would not occur.
} 
Shared control with independent director as the mediator. Suppose that $V_{1}^{E}+V_{1}^{V C} \neq$ $V_{3}^{E}+V_{3}^{V C}$, so that the independent director is never indifferent between the two proposed actions. Then, in equilibrium, at least one of the parties will propose Action 2, and it will be chosen by the independent director. ${ }^{27}$ Hence, the board's chosen action is efficient, even without any renegotiation. The parties are willing to make ex-ante investments if and only if

$$
\begin{aligned}
V_{2}^{E} & \geq I^{E}, \\
V_{2}^{V C} & \geq I^{V C} .
\end{aligned}
$$

Ex-ante investments and board control. The above discussion shows that both entrepreneur and shared control result in the efficient decision being made. However, they may have different implications for the parties' ex-ante investment decisions. While under entrepreneur control, the $\mathrm{VC}$ needs to make a time- $t_{1}$ transfer to the entrepreneur for the efficient action to be taken, no transfers are needed to achieve efficiency under shared control. Hence, from the ex-ante perspective, shared control gives the VC a higher payoff than entrepreneur control and makes it easier to convince the VC to contribute capital. Overall, the VC's payoff is the highest under VC control, followed by shared control, and is the lowest under entrepreneur control. The rankings from the entrepreneur's perspective are exactly the opposite.

Thus, a key departure from Aghion and Bolton (1992), which is what gives rise to the mediation role of the independent director, is the presence of a "middle-ground" action that is more efficient than the actions preferred by either the entrepreneur or the VC. Note, however, that if the most efficient action were instead the action preferred by either party (or if there were just two actions), then shared control would be equivalent to full control of that party and would implement the efficient decision, so shared control could not be worse.

It follows that if $I^{V C}$ is low, $I^{V C} \leq V_{2}^{V C}-\left(V_{3}^{E}-V_{2}^{E}\right)$, then the $\mathrm{VC}$ is willing to invest even under entrepreneur control. If, at the same time, $I^{E}$ is high $\left(I^{E}>V_{2}^{E}\right)$, the only way to ensure the entrepreneur's human capital investment is to give him control. However, as $I^{V C}$ increases above $V_{2}^{V C}-\left(V_{3}^{E}-V_{2}^{E}\right)$, entrepreneur control becomes insufficient to convince the $\mathrm{VC}$ to invest. As long as neither $I^{V C}$ nor $I^{E}$ are too high $\left(I^{V C} \leq V_{2}^{V C}\right.$ and $\left.I^{E} \leq V_{2}^{E}\right)$, shared control with an independent director as the mediator gives both the $\mathrm{VC}$ and the entrepreneur sufficient expected

\footnotetext{
${ }^{27}$ For example, the independent director cannot choose Action 1 in equilibrium. If he does, the entrepreneur will deviate from his equilibrium strategy and propose Action 2: the independent director will choose this action since he prefers it the most, and it will also benefit the entrepreneur because $V_{2}^{E}>V_{1}^{E}$.
} 
payoffs to induce their ex-ante investments, and also results in efficient decision-making by the board. Finally, if $I^{V C}$ is high enough (above $V_{2}^{V C}$ ), the only way to ensure the VC's investment is to give the $\mathrm{VC}$ full control, potentially sacrificing ex-post efficiency. The entrepreneur is willing to do this if his own outside option is relatively low, $I^{E} \leq V_{1}^{E}$.

\subsubsection{Empirical predictions}

A key implication from the above discussion is that as $I^{V C}$ increases relative to $I^{E}$, control will shift from (1) entrepreneur control, to (2) shared control, and then to (3) VC control. ${ }^{28}$ This gives rise to the following predictions, both over the life cycle and across firms.

First, over the firm's life cycle, the amount of capital contributed by VCs increases, whereas the importance and irreplaceability of the entrepreneur's human capital declines as the firm moves from developing the initial idea to the stage of a tangible, marketable product (e.g., Rajan, 2012; Kaplan, Sensoy, and Strömberg, 2009; Khanna and Mathews, 2016). This dynamics can be interpreted as an increase in $I^{V C}$ relative to $I^{E}$ over time, leading to our first prediction: ${ }^{29}$

Prediction 1. Within the firm's life cycle, control over the board will shift from (1) entrepreneur control in early financing rounds; (2) to shared control in intermediate financing rounds; and (3) to VC control in late financing rounds.

Second, across firms, the bargaining power of the VC relative to the entrepreneur (in the sense of the parties' outside opportunities from investing capital and human capital, respectively) corresponds to a higher $I^{V C}$ relative to $I^{E}$. Hence, our second prediction is as follows:

Prediction 2. Across firms, as the VC's bargaining power relative to the entrepreneur increases, control over the board will shift from (1) entrepreneur control for low VC bargaining power; (2) to shared control for intermediate levels of VC bargaining power; and then (3) to

\footnotetext{
${ }^{28}$ To see this, suppose that at the beginning of the game, the entrepreneur makes a take-it-or-leave-it offer to the $\mathrm{VC}$, offering him a given allocation of board control in exchange for capital. If $I^{V C}$ is low $\left(I^{V C} \leq V_{2}^{V C}-\left(V_{3}^{E}-V_{2}^{E}\right)\right)$, the entrepreneur will offer entrepreneur control, and the VC will agree. If $I^{V C}$ is not too high and not too low $\left(V_{2}^{V C}-\left(V_{3}^{E}-V_{2}^{E}\right)<I^{V C} \leq V_{2}^{V C}\right)$, the entrepreneur will offer shared control as long as his own outside option is not too high either $\left(I^{E} \leq V_{2}^{E}\right)$. Finally, if $I^{V C}$ is very high, whereas $I^{E}$ is low enough $\left(I^{V C}>V_{2}^{V C}\right.$ and $\left.I^{E} \leq V_{1}^{E}\right)$, the entrepreneur will offer VC control. In all other cases, no allocation of control is acceptable for both the $\mathrm{VC}$ and entrepreneur simultaneously, so an agreement will not be reached.

${ }^{29} \mathrm{Of}$ course, this prediction reflects dynamic changes, whereas our toy model is static, but it broadly captures the intuition that would arise in a dynamic model.
} 
VC control for high VC bargaining power.

Finally, the third prediction is that a negative shock to the required contribution of capital

by the $\mathrm{VC}$ (which can be thought of as a decrease in $I^{V C}$ relative to $I^{E}$ ) will change the allocation of control as follows:

Prediction 3. Following a negative shock to the amount of required VC capital, VC control becomes less likely and entrepreneur control becomes more likely.

\section{Main analysis}

This section presents our main results. Sections 6.1-6.3 test the three predictions of Section 5.2.1, and Section 6.4 examines the variation in the ex-ante likelihood of potential conflicts.

\subsection{Allocation of control within the firm's life cycle}

Note that Figure 3, presented earlier, is broadly consistent with the first prediction of Section 5.2.1: entrepreneurs tend to have control in early stages, VCs have control in late stages, and shared control is particularly common in intermediate stages.

To test the life cycle hypothesis directly, within a given firm, we calculate the transition probabilities between the three types of board control. In particular, we ask: conditional on a given allocation of control in one year, what is the likelihood the board will have a different allocation of control in the next year? This analysis is presented in Table 4. Panel A, which considers all financing years, is consistent with the life cycle hypothesis: conditional on a change in board control from one year to the next, entrepreneur control is $71 \%$ likely to switch to shared control $(31.36 /(31.36+12.85))$, whereas shared control is $85 \%$ likely to switch to VC control $(30.78 /(30.78+5.41))$. Conditional on the board being controlled by the VCs, VCs are $89 \%$ likely to retain control in the next year. The transition probabilities in Panel B, which only considers financing years in which there was a change in board size, are very similar.

We next present the regression analog of Figure 3, but with several important controls. In 
particular, we run the following regression:

$$
Y_{i t}=\beta_{0}+\sum_{s=1}^{8} \rho_{s} 1_{\mathrm{age}_{i t}=s}+\beta_{1} K_{i t}+X_{i t}+\varepsilon_{i t},
$$

where $Y_{i t}$ is one of the three indicators for board control and $1_{a g e_{i t}=s}$ is the dummy for whether the startup is of age $s$ relative to the year when the startup first raised VC equity financing. The excluded category is the year of first financing $(s=0)$. All financings for startups greater than 8 years old are winsorized to 8 years old. $K_{i t}$ is the log of the total capital raised by the startup in financing year $t$, while $X_{i t}$ contains industry-year and startup location fixed effects (location is defined as one of the nine Census divisions).

Table 5 presents the regression results, and Figure 5 plots the corresponding estimated coefficients. Consistent with Figure 3, entrepreneur control is most prevalent in the year of first VC financing and becomes exceedingly less likely as firm age increases and as the firm goes through financing rounds (columns 1 and 5), whereas VC control becomes exceedingly more likely (columns 3 and 7 ). The fraction of firms with shared control reflects the net of these two effects: as firm age/financing round increases, some firms switch from entrepreneur control to shared control (first effect), and others switch from shared control to VC control (second effect), and the overall change in shared control is positive only if the first effect happens at a higher speed than the second. Our model has no prediction about the relative speed of the two effects, and thus no prediction about the coefficients for shared control. In our sample, the first effect happens at a higher speed than the second in earlier years, but at a lower speed in later years, leading to the non-monotonic pattern in columns 2 and 6 .

Columns 4 and 8 show that the likelihood of having at least one independent director increases over the life cycle, as in Table 3. In earlier years, this matches the patterns for shared control and is consistent with independent directors joining as tie-breakers/mediators (if their only role were advisory, there would be no need to give them such voting power). The fact that the coefficients continue to increase in later stages suggests that even after control switches to VCs, these directors remain on the board or new independent directors join. This is consistent with their advisory role becoming more relevant, the dynamics that we explore below.

The fact that independent directors are not present in every firm suggests that unless these directors are playing a valuable role, such as mediation or advising, inviting them could be 
costly. Potential costs include the inefficiencies in collective decision-making due to a larger board size (e.g., Yermack, 1996) or the cost of director compensation. In what follows, we explore how the presence of independent directors is affected both by the firm's mediation needs and its advising needs.

\subsection{Allocation of control and VC bargaining power}

Proxies for VC bargaining power. To test the model's second prediction, we use two proxies to capture VC bargaining power relative to the entrepreneur. The first is based on valuations that VC investors pay for firms in the industry, while the second is based on "dry powder," i.e., the supply of VC capital in the geographical region. The reason we use industrylevel and region-level proxies, rather than startup or VC characteristics (such as the VC's reputation) is endogenous matching between VCs and startups: more reputable VCs tend to match with more promising startups, so the relative allocation of bargaining power is unclear.

To construct the first proxy, we consider each of the seven industry groups separately. Within each industry group, we calculate the average equity stake of the VCs (i.e., the ratio of capital invested by the VCs to post-money valuation) in early financing rounds across all firms during the previous year. We then split the observations within each industry group into three groups: (1) the top quartile of average VC equity in the previous year; (2) the bottom quartile; and (3) the middle 50\%. The top (bottom) quartile corresponds to the group with the highest (lowest) VC bargaining power within industry. The idea of this measure is that if the amount of capital contributed by the VC is determined by the firm's production needs and not by the parties' bargaining power, then a higher average VC equity stake corresponds to higher VC bargaining power in negotiations over the firm's valuation.

To construct the second proxy, we use a measure of "dry powder," i.e., the supply of VC capital available for investment, at the geographical location level. Specifically, we consider nine Census divisions (which we refer to as "regions") and allocate each startup and each VC to a given region based on the location of the startup and of the VC firm's headquarters, respectively. Within each region, we measure dry powder in a given year as the total capital raised by all VC funds in this region since 1990 and up to this year, minus the total capital invested into startups located in this region from 1996 up to this year (the six-year lag captures the fact that 
the VC fund takes several years to invest the capital it raised.) We then split all observations within each region into three groups: (1) the top quartile of dry powder in the previous year; (2) the bottom quartile; and (3) the middle 50\%. Higher dry powder corresponds to a higher supply of VC capital in the region, and hence lower VC bargaining power.

Both proxies reflect relative bargaining power, i.e., changes in the VC's bargaining power relative to the entrepreneur's bargaining power. Our preferred measure is the equity-based proxy since the dry powder measure is noisier. ${ }^{30}$

Results. The results based on the first (second) proxy are presented in Panel A (Panel B) of Table 6. Columns 1-4 of each panel correspond to the quartile splits described above, and in columns 5-8, we similarly split the sample period into quintiles within industry/region. The excluded category is always the middle of the distribution. The outcomes of interest are board control and the presence of independent directors in the first financing round. We do not consider subsequent financing rounds because the allocation of control in them depends on the allocation of control in the previous rounds, which makes the results harder to interpret. All regressions include the log of capital raised and industry and region fixed effects. We do not include year fixed effects because by construction, the variation in our bargaining power measures comes from the time-series variation within an industry/region.

Panel A shows that entrepreneur control becomes increasingly less likely as the VC's bargaining power relative to the entrepreneur increases based on the equity stake proxy. For example, the fraction of startups with entrepreneur control in the lowest (highest) quartile of VC bargaining power is higher (lower) than in the middle of the distribution by 0.07 (0.13). These effects are economically significant, given that the average frequency of entrepreneur-controlled boards in the first financing round is 0.46 . In contrast, the fraction of VC-controlled boards increases with VC bargaining power: it is by 0.05 lower ( 0.11 higher) in the bottom (top) quartile than in the middle of the distribution, with the sample average of 0.21 .

The relation between VC bargaining power and shared control reflects the net of these two

\footnotetext{
${ }^{30}$ There are two reasons why the dry power proxy is noisier than the equity-based measure. First, in order to have more than annual variation, we assigned VC funds to geographic regions based on their headquarters location. Most VCs are able to invest nationally and may have multiple offices making investments. Second, because it is challenging to observe the exact VC fund that invests in a startup, the capital raised by startups in the region is an imperfect measure of capital deployed by previously closed VC funds. For example, some investors in equity financings are corporate VCs or individuals that do not invest out of traditional funds.
} 
effects, i.e., on whether, as VC bargaining power increases, entrepreneur control is replaced by shared control at a higher speed than shared control is replaced by VC control (see Section 6.1 for a similar discussion about the life cycle dynamics). In our sample, the first effect occurs at a higher speed, so the likelihood of shared control slightly increases with VC bargaining power.

The corresponding results for the dry powder proxy in Panel B are noisier, but are all broadly consistent with those in Panel A.

\subsection{Introduction of cloud computing and the shift of board control}

We test the third prediction from Section 5.2.1 by exploiting the introduction of Amazon Web Services (AWS) in early 2006. This technological shock significantly lowered the cost of forming new internet-based startups by removing the need for large upfront investments in hardware. As Ewens, Nanda, and Rhodes-Kropf (2018) show, the introduction of AWS increased the prevalence of a "spray and pray" investment approach, whereby VC investors provide lower amounts of funding to a larger number of startups. In the context of Section 5, it can thus be viewed as a negative shock to $I^{V C}$ relative to $I^{E}$, which would predict a shift from VC control to entrepreneur control. Since AWS had a particularly strong effect on early stage financings, we focus on board control in the Series A financing event.

We follow the approach of Ewens, Nanda, and Rhodes-Kropf (2018) in classifying the 28 industry-segments in VentureSource into those that benefited the most from AWS ("treated") and all others ("control"); see Table 2 in their paper. We then perform a differences-in-differences estimation, where a firm-year observation belongs to the post-period if the first VC financing happened between 2006 and 2010. Ewens, Nanda, and Rhodes-Kropf (2018) provide several tests validating the parallel trends assumption, and also discuss why the results cannot be explained by other changes that occurred around 2006 (see Section 3.2 and Section 5 of their paper); the same arguments apply in our setting as well. Since their paper shows that AWS resulted in a lower probability of VCs taking board seats in their portfolio firms, we restrict the sample to boards that include at least one VC director. This allows us to distinguish changes in board control (intensive margin) from changes in the presence of VCs on the board per se (extensive margin), although the results are almost unchanged if we consider the entire sample.

Table 7 presents the results. Consistent with the prediction, there is a significant $(30 \%=$ $.06 / .20)$ increase in the likelihood of entrepreneur control and a significant $(26 \%=.095 / .37)$ 
decrease in the likelihood of VC control in treated firms relative to control firms. ${ }^{31}$

Trends in board control. We now return to the discussion of trends presented in Figure 4. The above analysis suggests that the introduction of AWS has been at least partly responsible for the shift of board control from founders to VCs over the last decades. Relatedly, Aggarwal, Eldar, Hochberg, and Litov (2021) tie this technological change to the shift towards dual-class IPOs. However, the trends in board control are also observed in industries not affected by AWS (see Figure A9 for the healthcare industry in the Internet Appendix). We hypothesize that another important reason for these trends has been the increased availability of private equity capital. First, the 1996 deregulation of private equity markets made it easier for startups to raise capital from out-of-state investors and for $\mathrm{VC}$ funds to raise larger amounts of capital (Ewens and Farre-Mensa, 2020). Second, non-traditional investors, such as mutual funds, hedge funds, and sovereign wealth funds, have become increasingly active in making direct private equity investments in startups (e.g., Fang, Ivashina, and Lerner, 2015; Chernenko, Lerner, and Zeng, 2017). Both of these changes increased the outside opportunities of entrepreneurs relative to VCs (i.e., increased $I^{E}$ in the model of Section 5), which could have increased entrepreneurs' bargaining power and led to a shift of board control from investors to entrepreneurs.

\subsection{Ex-ante conflicts and mediation}

If independent directors are added to mediate future conflicts between entrepreneurs and VCs, their presence should be particularly likely when the probability of conflicts is ex-ante high.

One important source of conflict is the decision about whether to replace the founder, and the ex-ante potential of such a conflict is higher if the VC investor has a reputation for replacing founders of its portfolio firms in the past. To construct a measure of such reputation, for each VC investor and quarter-year, we calculate the number of CEOs replaced in firms in the VC's portfolio up to that point and divide it by the overall number of firms in the VC's portfolio up to that point. We then define VCs who are in the top quartile based on this ratio as "top CEO replacers" in the respective quarter-year. For each startup-financing year, our key explanatory variable is the dummy "Has top CEO replacer," which equals one if at least one of the investors

\footnotetext{
${ }^{31} \mathrm{As}$ in previous tests, the model has no specific prediction for the change in shared control: it is expected to become more likely than VC control, but less likely than entrepreneur control, and the net effect of AWS on the prevalence of shared control depends on the relative strength of these two effects.
} 
in that financing is identified as a top CEO replacer.

Column 1 of Table 8 shows that if the first financing round involves at least one top CEO replacer, there is a 19\% (.075/.37) higher likelihood of an independent director being on the board. It is possible that a VC's past aggressiveness in replacing the CEO is correlated with the VC's experience and, in turn, bargaining power. Hence, in column 2, we control for the VC's experience and find that the coefficient on top CEO replacer changes little and remains significant. Moreover, columns 3 and 4 show that the presence of a top CEO replacer is associated with a significantly higher (e.g., 19\%=.034/.18 in column 3) likelihood of having the independent director in a tie-breaking role. ${ }^{32}$

These results give support to the mediation role and distinguish it from other potential roles of independent directors. In particular, they emphasize that differently from public firms, where independent directors help protect investors from the opportunistic behavior of executives (the monitoring role), independent directors in startups help protect both executives and investors from the opportunism of the other party (the mediation role).

As another measure of ex-ante conflicts, we ask whether the VCs and executives have interacted in the past, in particular, whether the VCs have ever invested in a startup that was founded or headed by the current founder or CEO. Since such past interactions are more likely if the executives are former founders or CEOs, and this could be correlated with executives' bargaining power, we control for the past founder/CEO status in these regressions. Columns 7-8 of Table 8 show that the board is less likely to have an independent director in a tie-breaking role if such past interactions took place. This provides suggestive evidence for the idea that a repeated investment relationship is more likely when the VC and executives have similar views and trust each other, which reduces the need for mediation.

\section{Mediation and advisory roles over the life cycle}

In addition to mediation, independent directors could play an advisory role, complementing the value-add of VC investors in hiring, strategy, and investment decisions. Our previous arguments

\footnotetext{
${ }^{32}$ The outcome variable for this test is an indicator for shared control with an independent director. In particular, it is set to zero for deadlock boards, another case we classify as shared control (see footnote 17). This is because such board composition is not effective at resolving the disputes between the two parties and can even exacerbate them by causing deadlock.
} 
suggest that the mediation role is relatively more important in earlier stages of the life cycle. In contrast, directors who join in later stages, once VCs have control over the board, are more likely to be playing an advisory role and helping the professionalization of the startup. If this is the case, we expect independent directors' characteristics to change over the life cycle, to match the mediation role earlier on and the advisory role later on.

To examine this prediction, we collect the data on independent director characteristics, which is summarized in Table 9. For independent directors found in VentureSource $(81 \%$ of the sample), we often have a biographical string (e.g. CEO Widgets Inc.; CFO Robots LLC). To capture their managerial experience, we look at the number of past C-level and VP-level positions mentioned in this biographical string. We also match our data with BoardEx and document whether a director has ever served on the board of a publicly traded firm.

Table 9 reveals that a quarter of independent directors are former entrepreneurs. An average director has held 1.2 C-level positions and 0.6 VP-level positions, and 8.6\% of directors have served on the board of a public firm. Table 10 examines these characteristics over the life cycle. Panel A defines directors as "joining a late-stage board" if they joined at least five years after the first VC financing. It shows that directors with C-level, VP-level, and especially those with public-board experience are significantly more likely to join later (columns 3-5), consistent with the advising and professionalization of the startup becoming more important in later stages. $^{33}$ On the other hand, former founders are substantially more likely to join early-on: their founder experience is likely to predispose them towards entrepreneurs and help withstand the pressure to be VC-friendly, which could make them more effective mediators. In addition, this is consistent with the changing advisory needs of the startup: entrepreneurial experience is useful in younger firms, whereas managerial-level and public-board experience is useful in more developed startups.

In Panel B, we relate independent directors' characteristics to the allocation of board control at the time they join, rather than to firm age. The outcome variable is whether the director joins when the board has either shared or entrepreneur control (i.e., the director joins as a tie-breaker or in preparation to be a tie-breaker), and we include firm age fixed effects to distinguish board control from the effect of age explored in Panel A. Most importantly, we see

\footnotetext{
${ }^{33}$ We control for the total number of jobs listed in the director's biography because longer biographical strings are mechanically more likely to mention executive-level positions.
} 
that independent directors who join the board during this stage are significantly less likely to have prior professional connections with either VCs or entrepreneurs (Section A4 in the Internet Appendix describes how we measure past connections). This is reasonable, given that unconnected directors are more likely to be impartial and hence be more effective mediators. In addition, and consistent with Panel A, directors joining in later stages (the stage of VC control) are more likely to have managerial and public board experience and are less likely to be former founders. Overall, Table 10 suggests that independent director characteristics match the roles they are expected to play, and that these roles change over the life cycle.

As another test, we ask whether the characteristics of the VCs predict the use of independent directors over time: if independent directors are playing an advisory role, they should be in higher demand by low-experience VCs. Figure 6 shows that there is little difference in the use of independent directors by experienced vs. inexperienced VCs in the first financing round. This is consistent with the mediation role being relatively more important at that stage and VC experience not being directly related to the need for mediation. In contrast, in later rounds, the boards of inexperienced VCs are more likely to add new independent directors than those of experienced VCs, consistent with the advisory role becoming relatively more important. However, these results need to be interpreted with caution since there is a positive correlation between $\mathrm{VC}$ experience and $\mathrm{VC}$ bargaining power.

Finally, we explore the idea that independent directors facilitate the professionalization of the firm from a startup to being a public company (Hellmann and Puri, 2002; Rajan, 2012). Figure 7 explores the evolution of the board for two subsamples: firms that exit via an IPO (277 firms in our sample) and those that do not. The comparison of the two figures reveals that firms doing an IPO significantly increase their board size approaching the IPO compared to other firms: the average board size at later stages is 7 for IPO exits and 5.5 for other cases. In addition, IPO firms add more independent directors: an average startup that exits via an IPO has two independent directors at later stages, compared to only one for other firms. A potential explanation is the regulatory requirement to have a majority of independent directors for publicly listed firms: adding such directors in advance, in anticipation of going public, allows them to learn about the firm and be more effective after the IPO. ${ }^{34}$

\footnotetext{
${ }^{34}$ There is also some evidence that female independent directors are more likely than male directors to join later in the life cycle and to join firms that exit through an IPO.
} 


\section{Discussion and robustness}

Director connections. Following up on our discussion of director independence in Section 5.1, we show that our results are robust to accounting for potential ties between directors.

We start by analyzing the data on past professional connections. Each pair of "investor and independent director" and "executive and independent director" on the current board can have a connection via any past investment activity, board activity, or employment within the VC industry, and we then classify the independent director in such a pair to be "connected." Section A4 in the Internet Appendix provides details on how we identify past connections. We next redefine board control by considering a director connected to VCs (entrepreneurs) through his past professional experience as a representative of VCs (entrepreneurs).

Table A9 in the Internet Appendix presents the summary statistics on connections. Connections to entrepreneurs are rare (1\% of independent directors), so among the connected independent directors, most are connected to VCs. The fraction of independent directors who are connected increases over financing rounds, from $20 \%$ in the first round to $30 \%$ in the fourth round. Given these connections, around 10\%-13\% (1\%-3\%) of startups that were previously classified as having shared control are now reclassified as having VC (entrepreneur) control.

Table 11 repeats the analysis in Tables 5 and 6, respectively, but using these new definitions of board control. This analysis reveals very similar results to those obtained without the director connections data. There is a pronounced monotonic positive (negative) relation between startup financing round and VC (entrepreneur) control over the board. Similarly, there is a monotonic positive (negative) relation between proxies for VC bargaining power and VC (entrepreneur) control over the board. In unreported results, we also show that the effect of the AWS shock is weakly stronger when using the director connections data. Thus, our main conclusions are robust to this more conservative definition of independent directors.

In addition to analyzing connections through the startup industry, we performed a more in-depth analysis of potential ties between directors (educational, employment, and social) for a small random sample using LinkedIn and Google search. This analysis did not reveal any relevant connections beyond those already identified in our data on professional connections (see Section A4 in the Internet Appendix). 
Equity ownership. One concern is that the dynamics that we document can be explained by simple shifts in equity ownership. To address this, we repeat the main analyses controlling for ownership. ${ }^{35}$ Table A7 in the Internet Appendix is similar to Table 5 but includes the entrepreneur's equity stake as a control, and Figure A15 plots the corresponding coefficients. As expected, the entrepreneur's stake is significantly positively (negatively) related to the likelihood of entrepreneur (VC) control. However, entrepreneur (VC) control continues to decrease (increase) with age and financing rounds, confirming that the dynamics of control is not a mechanical reflection of VCs' increased ownership over the life cycle. Moreover, Figure A16 in the Internet Appendix shows that changes in board control due to changes in the entrepreneur's ownership are substantially smaller in magnitude than changes in board control over the life cycle. Last, our results connecting bargaining power and board control are also robust to controls for the entrepreneur's ownership stake (Table A8 in the Internet Appendix).

Other robustness tests. While our sample creation requires the filing of Form D during the startup's first VC financing, it does not require the filing of Form D with every subsequent financing. This means that for startups that stopped filing Form D at a certain point, we rely solely on VentureSource to identify any changes to the board after that point. To explore whether the presence of such stale boards affects the results, we drop a startup from the sample if it has a known VC financing, but no Form D filed in the previous two years. The resulting sample has 7,428 startups (4.5\% sample loss) and the results are quantitatively unchanged (Figures A13 and A14 and Table A6 in the Internet Appendix). Next, our results are robust to the exclusion of firms that exited via an IPO. There are fewer than 300 such firms in our sample. Finally, in unreported regressions and figures, we find the results are robust to separately considering each of the two most represented industries in our sample, IT and healthcare.

Conflicts between VCs. In our analysis, we follow Kaplan and Strömberg (2003) and treat all VCs investing in the firm as fully aligned. There are several reasons why the VC-entrepreneur conflicts are likely to be first-order relative to within-VC conflicts, especially in earlier stages of the life cycle. First, early-stage investors have some influence over the choice of subsequent

\footnotetext{
${ }^{35}$ For each financing round where the valuation is known, we calculate the equity stake retained by the existing investors, which we denote by $e_{t}$. We can then track the equity stake retained by the entrepreneurs after round $s$ as the product of $e_{t}$ for $t=1, \ldots, s$. When doing this, we ignore the rounds for which valuations are missing, so our equity stake control is an upper bound for the true entrepreneur ownership.
} 
investors and are likely to pick those with whom they expect to agree (see also footnote 5 in Kaplan and Strömberg, 2003). Second, all VCs have a preference for a relatively quick exit, which aligns their interests for many decisions. Nevertheless, conflicts between VCs might arise as well, especially in later financing rounds. While exploring such conflicts is beyond the scope of this paper, an interesting possibility is that in later stages of the life cycle, independent directors' role is not only advisory, but also to mediate among different investors.

\section{Conclusion}

This paper studies the dynamics of VC-backed startup boards using a novel dataset of 7,780 startups from 2002 to 2017. We examine the evolution of board control and investigate whether the role of independent directors changes over the startup life cycle. Independent directors on startup boards are widespread and often have substantial voting power: in many cases, neither the VC directors nor the entrepreneurs have a majority of board seats, and independent directors hold a tie-breaking vote. Moreover, such shared control is a key step in the transition of board control over the life cycle.

Our analysis suggests that independent directors are playing a unique "mediation" role, mediating and resolving potential conflicts between VCs and entrepreneurs. Moreover, independent directors' role evolves over the life cycle, from mediation in earlier stages to advising in later stages. We also document that over the years, control over boards has shifted from VCs to entrepreneurs, consistent with the general trend toward lower VC bargaining power that has been documented in other studies. However, the prevalence of boards with shared control and independent directors as tie-breakers has remained high.

Overall, our results provide evidence for a previously under-explored role of independent directors. They highlight that a dynamic theory of shifts in the allocation of control that involves the mediation role could be an interesting direction for future theoretical research. Furthermore, the mediation role could be important for other types of firms with two or more large blockholders that have conflicting interests. Exploring this role outside of VC-backed startups could be another fruitful avenue for future research. 


\section{References}

Adams, Renée B., and Daniel Ferreira, 2007, A Theory of Friendly Boards, The Journal of Finance 62, 217-250.

Adams, Renee B., Benjamin E. Hermalin, and Michael S. Weisbach, 2010, The Role of Boards of Directors in Corporate Governance: A Conceptual Framework and Survey, Journal of Economic Literature 48, 58-107.

Aggarwal, Dhruv, Ofer Eldar, Yael Hochberg, and Lubomir P. Litov, 2021, The Rise of Dual-Class Stock IPOs, Discussion paper, National Bureau of Economic Research.

Aghion, Philippe, and Patrick Bolton, 1992, An Incomplete Contracts Approach to Financial Contracting, The Review of Economic Studies 59, 473-494.

Amornsiripanitch, Natee, Paul A. Gompers, and Yuhai Xuan, 2019, More than Money: Venture Capitalists on Boards, The Journal of Law, Economics, and Organization 35, 513-543.

Atanasov, Vladimir, Vladimir Ivanov, and Kate Litvak, 2012, Does Reputation Limit Opportunistic Behavior in the VC Industry? Evidence from Litigation against VCs, The Journal of Finance 67, 2215-2246.

Baker, Malcolm, and Paul A. Gompers, 2003, The Determinants of Board Structure at the Initial Public Offering, The Journal of Law and Economics 46, 569-598.

Blair, Margaret M., 2014, Boards of Directors as Mediating Hierarchs, Seattle University Law Review 38, 297.

— , and Lynn A. Stout, 2001, Trust, Trustworthiness, and the Behavioral Foundations of Corporate Law, University of Pennsylvania Law Review 149, 1735-1810.

Boone, Audra L., Laura Casares Field, Jonathan M. Karpoff, and Charu G. Raheja, 2007, The Determinants of Corporate Board Size and Composition: An Empirical Analysis, Journal of Financial Economics 85, 66-101.

Boschner, Steven E., and Amy L. Simmerman, 2016, The Venture Capital Board Member's Survival Guide: Handling Conflicts Effectively While Wearing Two Hats, Del. J. Corp. L. 41, 1.

Broughman, Brian J., 2010, The Role of Independent Directors in Startup Firms, Utah Law Review 2010, 461. 
- 2013, Independent Directors and Shared Board Control in Venture Finance, Review of Law \& Economics 9, 41-72.

Burkart, Mike, Salvatore Miglietta, and Charlotte Ostergaard, 2021, Why Do Boards Exist? Governance Design in the Absence of Corporate Law, Working paper.

Chernenko, Sergey, Josh Lerner, and Yao Zeng, 2017, Mutual Funds as Venture Capitalists? Evidence from Unicorns, NBER Working Paper.

Cogen et al., Douglas N., 2013, Corporate and securities alert: In re Trados - important lessons for directors on fiduciary duties to common stockholders, Fenwick $\mathbb{E}$ West LLP.

Coles, Jeffrey L., Naveen D. Daniel, and Lalitha Naveen, 2008, Boards: Does One Size Fit All?, Journal of Financial Economics 87, 329-356.

Cornelli, Francesca, and Oğuzhan Karakaş, 2015, CEO Turnover in LBOs: The Role of Boards, Working paper.

Denis, David J., and Atulya Sarin, 1999, Ownership and Board Structures in Publicly Traded Corporations, Journal of Financial Economics 52, 187-223.

Donaldson, Jason R., Nadya Malenko, and Giorgia Piacentino, 2020, Deadlock on the Board, The Review of Financial Studies 33, 4445-4488.

Eldar, Ofer, Jillian Grennan, and Katherine Waldock, 2020, Common Ownership and Startup Growth, Duke Law School Public Law 83 Legal Theory Series.

Ewens, Michael, and Joan Farre-Mensa, 2020, The Deregulation of the Private Equity Markets and the Decline in IPOs, The Review of Financial Studies 33, 5463-5509.

Ewens, Michael, Ramana Nanda, and Matthew Rhodes-Kropf, 2018, Cost of Experimentation and the Evolution of Venture Capital, Journal of Financial Economics 128, 422-442.

Fang, Lily, Victoria Ivashina, and Josh Lerner, 2015, The Disintermediation of Financial Markets: Direct Investing in Private Equity, Journal of Financial Economics 116, 160-178.

Feld, Brad, and Jason Mendelson, 2019, Venture Deals: Be Smarter than Your Lawyer and Venture Capitalist (John Wiley \& Sons).

Fich, Eliezer M, and Anil Shivdasani, 2006, Are Busy Boards Effective Monitors?, Journal of Finance 61, 689-724. 
Field, Laura, Michelle Lowry, and Anahit Mkrtchyan, 2013, Are Busy Boards Detrimental?, Journal of Financial Economics 109, 63-82.

Fried, Jesse M., and Mira Ganor, 2006, Agency Costs of Venture Capitalist Control in Startups, New York University Law Review 81, 967-1025.

Gompers, Paul A., Will Gornall, Steven N. Kaplan, and Ilya A. Strebulaev, 2020, How Do Venture Capitalists Make Decisions?, Journal of Financial Economics 135, 169-190.

Gorman, Michael, and William A. Sahlman, 1989, What Do Venture Capitalists Do?, Journal of Business Venturing 4, 231-248.

Graham, John R., Hyunseob Kim, and Mark Leary, 2020, CEO-Board Dynamics, Journal of Financial Economics 137, 612-636.

Grossman, Sanford J., and Oliver D. Hart, 1986, The Costs and Benefits of Ownership: A Theory of Vertical and Lateral Integration, Journal of Political Economy 94, 691-719.

Harford, Jarrad, and Robert J. Schonlau, 2013, Does the Director Labor Market Offer Ex Post Settling-Up for CEOs? The Case of Acquisitions, Journal of Financial Economics 110, 18-36.

Hart, Oliver D., and John Moore, 1990, Property Rights and the Nature of the Firm, Journal of Political Economy 98, 1119-1158.

Hellmann, Thomas, and Manju Puri, 2002, Venture Capital and the Professionalization of Start-Up Firms: Empirical Evidence, The Journal of Finance 57, 169-197.

Hermalin, Benjamin E., and Michael S. Weisbach, 1998, Endogenously Chosen Boards of Directors and Their Monitoring of the CEO, The American Economic Review 88, 96-118.

Hochberg, Yael V., 2012, Venture Capital and Corporate Governance in the Newly Public Firm, Review of Finance 16, 429-480.

Iliev, Peter, and Michelle Lowry, 2020, Venturing beyond the IPO: Financing of Newly Public Firms by Venture Capitalists, The Journal of Finance 75, 1527-1577.

Kaplan, Steven N., Berk A. Sensoy, and Per Strömberg, 2009, Should Investors Bet on the Jockey or the Horse? Evidence from the Evolution of Firms from Early Business Plans to Public Companies, The Journal of Finance 64, 75-115. 
Kaplan, Steven N., and Per Strömberg, 2003, Financial Contracting Theory Meets the Real World: An Empirical Analysis of Venture Capital Contracts, The Review of Economic Studies $70,281-315$.

— , 2004, Characteristics, Contracts, and Actions: Evidence from Venture Capitalist Analyses, The Journal of Finance 59, 2177-2210.

Khanna, Naveen, and Richmond D. Mathews, 2016, Posturing and Holdup in Innovation, The Review of Financial Studies 29, 2419-2454.

Lerner, Josh, 1995, Venture Capitalists and the Oversight of Private Firms, The Journal of Finance 50, 301-318.

Montag, Alexander, 2021, Attention, Please! Outside Expertise and Entrepreneurial Success, Working paper.

Rajan, Raghuram G., 2012, Presidential Address: The Corporation in Finance, The Journal of Finance 67, 1173-1217.

Sahlman, William A., 1990, The Structure and Governance of Venture-Capital Organizations, Journal of Financial Economics 27, 473-521.

Venugopal, Buvaneshwaran, and Vijay Yerramilli, 2020, Outside Directors at Early-Stage Startups, Working paper.

Villalonga, Belén, María-Andrea Trujillo, Alexander Guzmán, and Neila Cáceres, 2019, What are Boards for? Evidence from Closely Held Firms in Colombia, Financial Management 48, 537-573.

Weisbach, Michael S., 1988, Outside Directors and CEO Turnover, Journal of Financial Economics 20, 431-460.

Yermack, David, 1996, Higher Market Valuation of Companies with a Small Board of Directors, Journal of Financial Economics 40, 185-211. 


\section{Tables and Figures}

Figure 1: Board composition over the life cycle: counts

The figure reports the average and median number of board seats held by executives, independent directors, and investors. The x-axis is the years since the first VC equity financing.

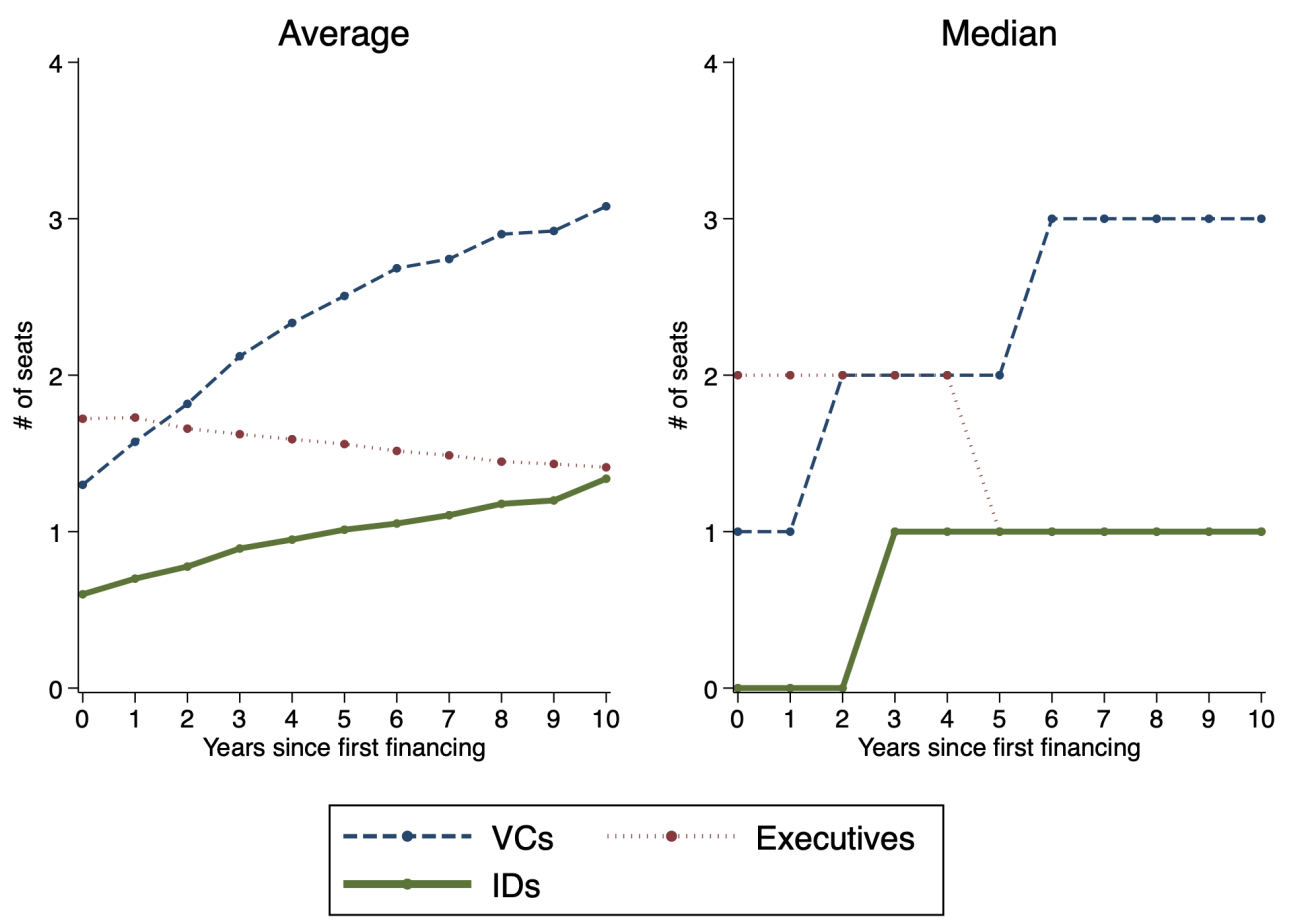


Figure 2: Board composition over the life cycle: percentage

The figure reports the average and median fraction of board seats held by executives, independent directors, and investors. The $\mathrm{x}$-axis is the years since the first VC equity financing.
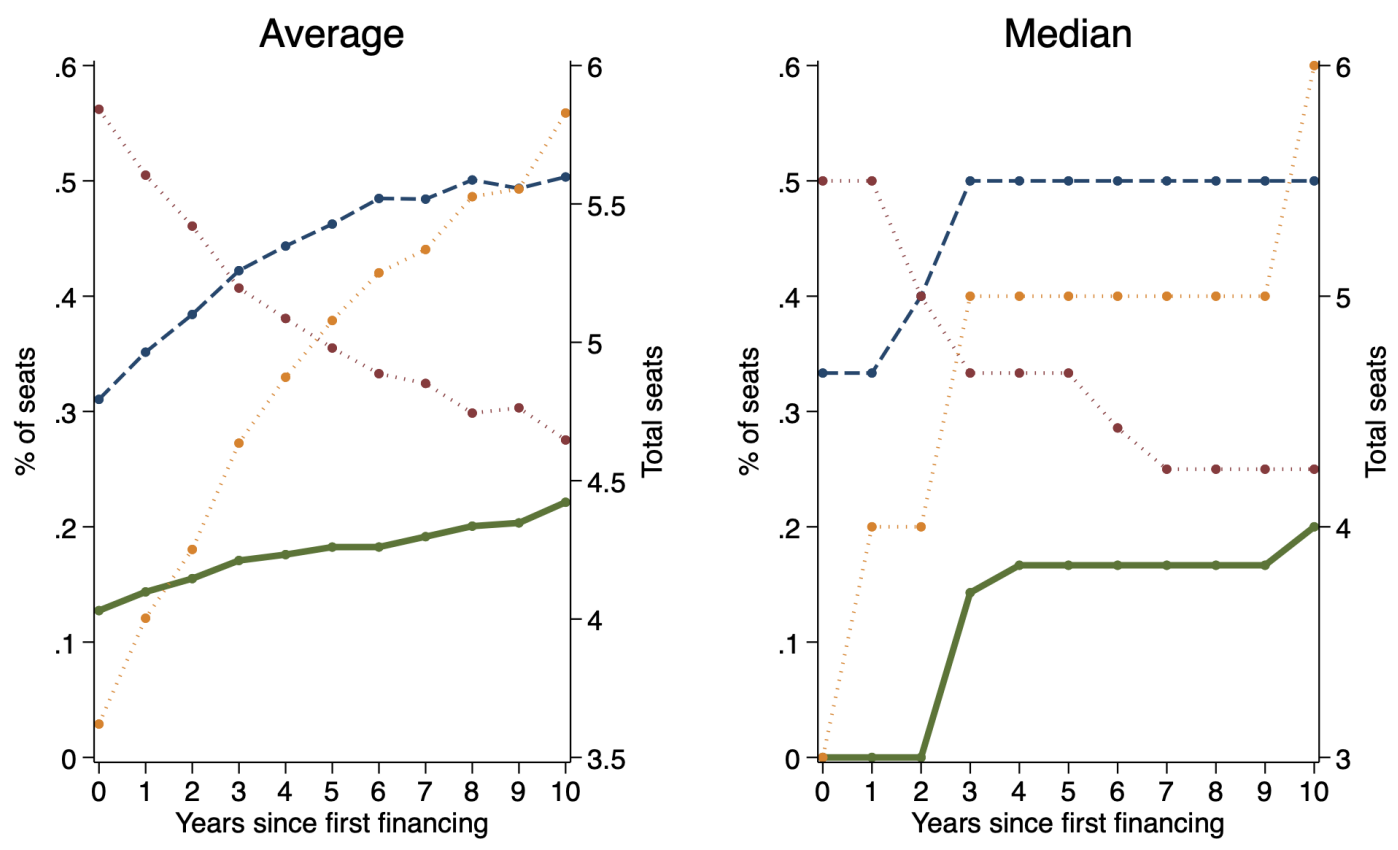

\begin{tabular}{|c|c|}
\hline$---\cdots---$ VCs & Executives \\
\hline IDs & \# seats \\
\hline
\end{tabular}


Figure 3: Board control over the life cycle

The figure reports the percentage of startups with a given allocation of board control by financing round (left) and firm age (right), where ago 0 is the year of first VC equity financing. "Entrepreneur" is the percentage of startups where executives/entrepreneurs control the board, "VC" is the percentage of startups where investors control the board, and "Shared" is the percentage of startups in which neither VCs nor entrepreneurs control the board. The definitions of board control are given in Section 3.
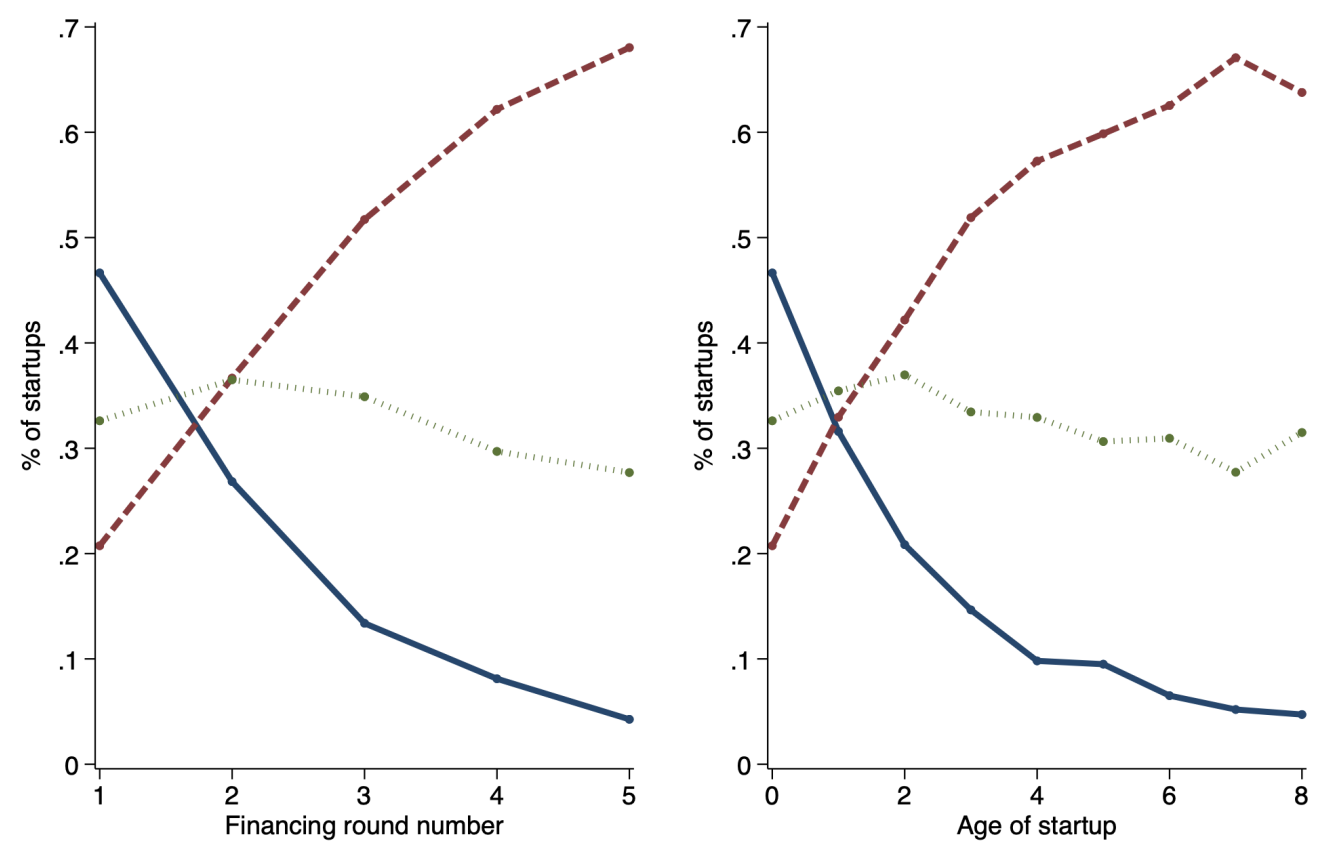

Entrepreneur =-=a-=- VC

Shared 


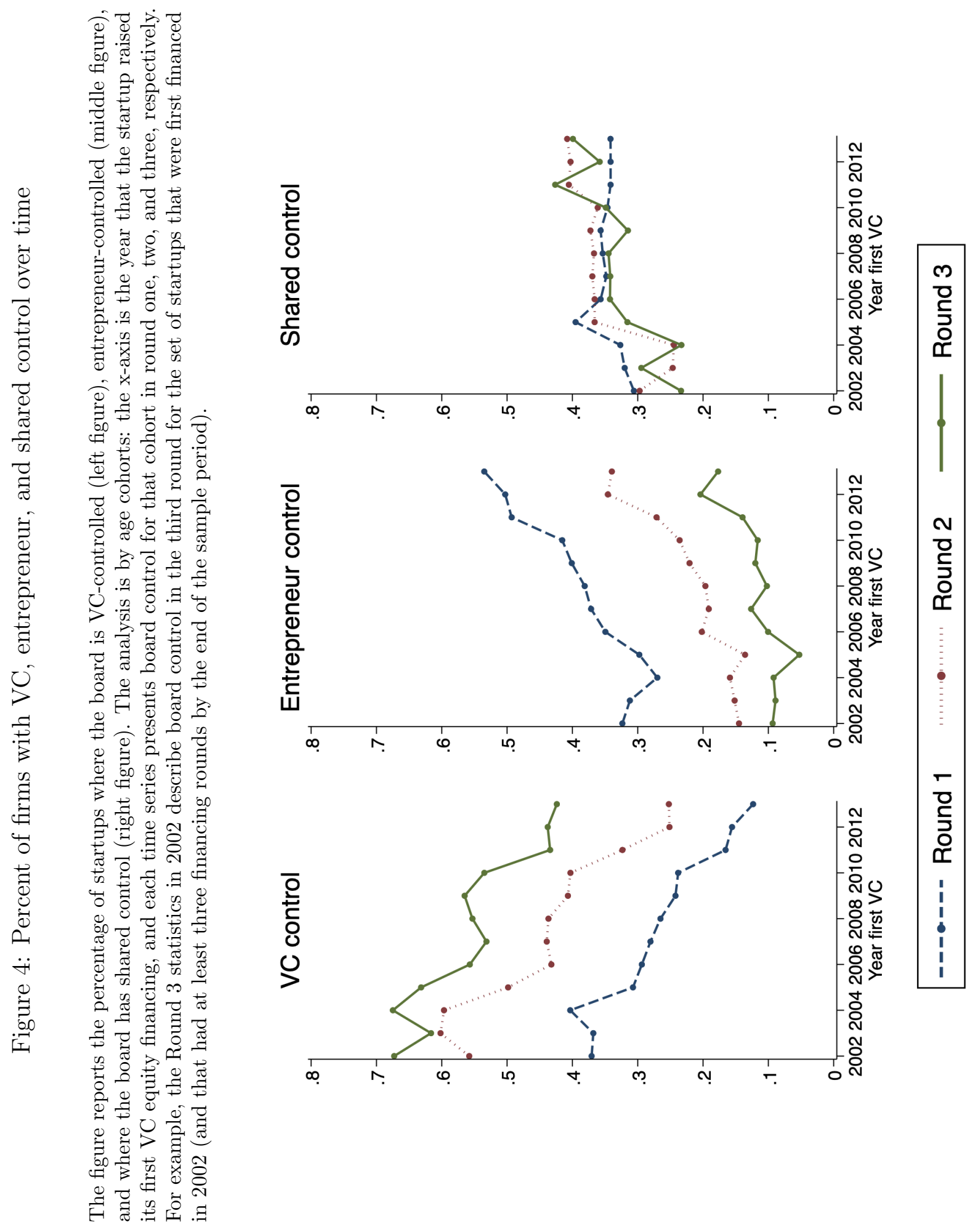


Figure 5: Board control over the life cycle: Regression estimates

The figure reports the coefficient estimates (and 95\% confidence intervals with robust standard errors) from the regressions reported in Table 5. The top figure reports coefficients from columns (1)-(3) for firm age, and the bottom figure reports coefficients from columns (5)-(7) for financing round. Controls in the regression include log capital raised, fixed effects for year-industry, and location fixed effects.

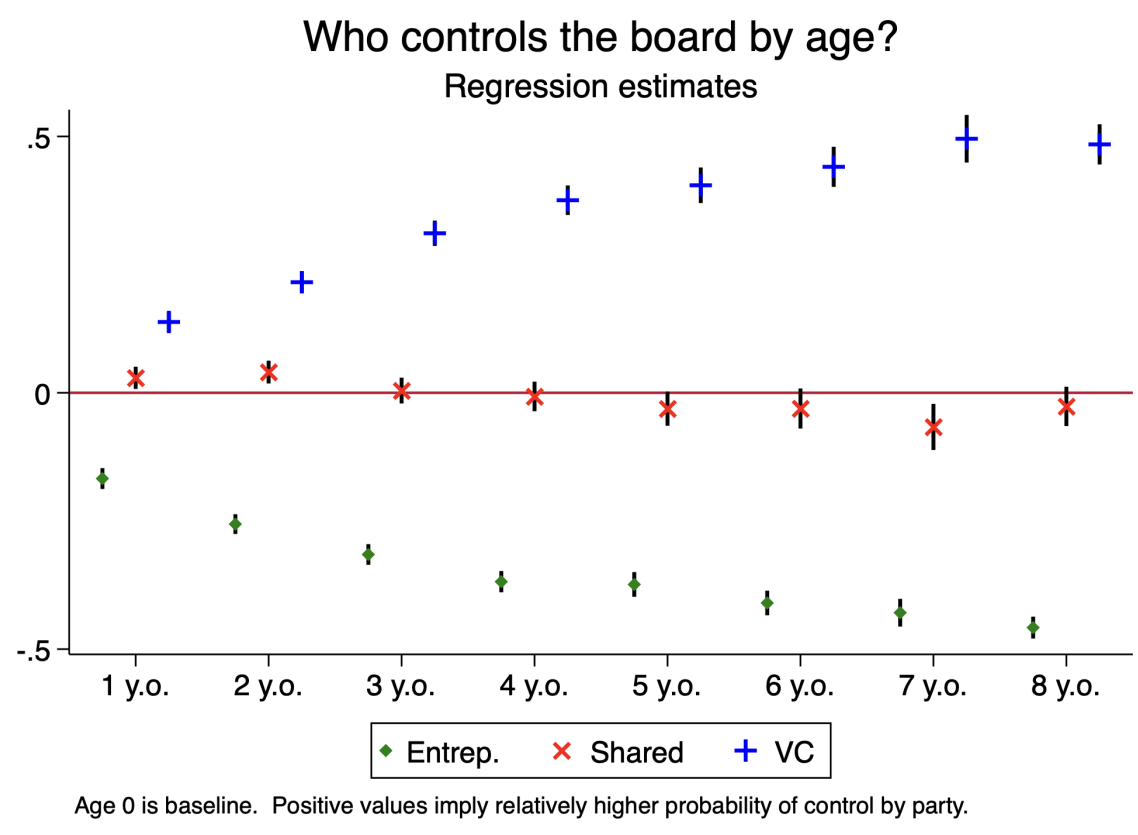

Who controls the board over financing rounds?

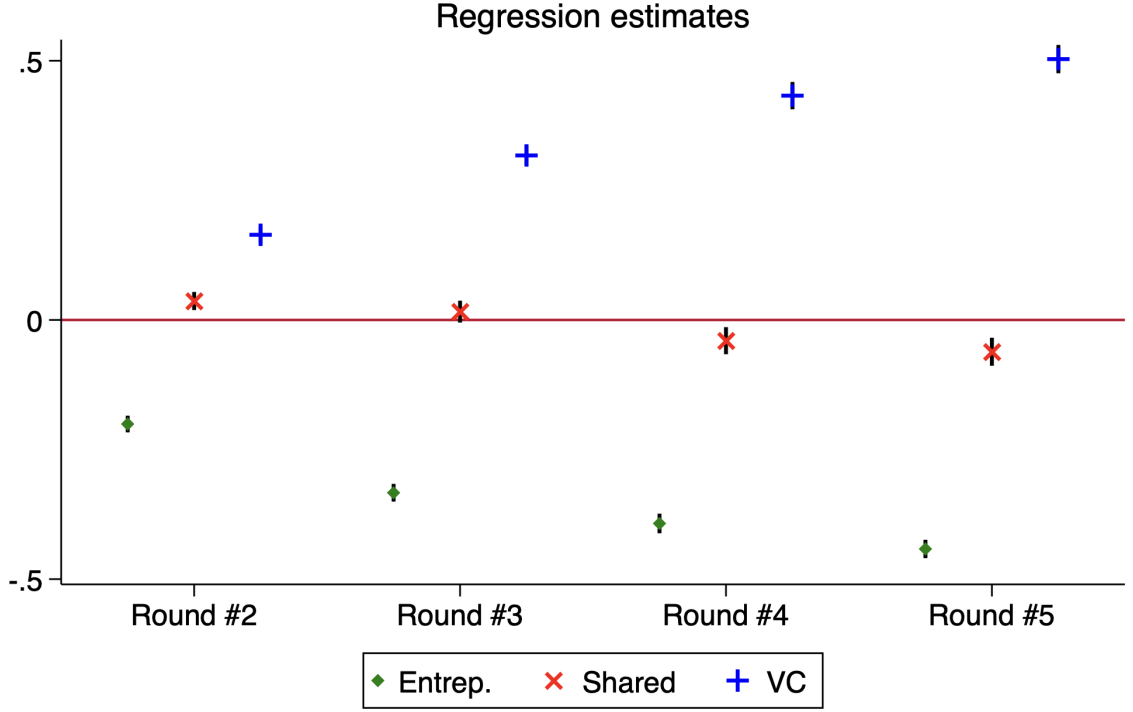

Round 1 is baseline. Positive values imply relatively higher probability of control by party. 
Figure 6: Early-stage VC experience and use of independent directors over time

The figure reports the percentage of boards at each financing round that have at least one new independent director as of that financing. We split the sample into two parts using the investment experience of the first round lead VC. If the total number of deals completed by the first round lead VC is above the sample median, then the startup is categorized as "Early exp. VC." If it is below the sample median, the startup is categorized as "Early inexp. VC."

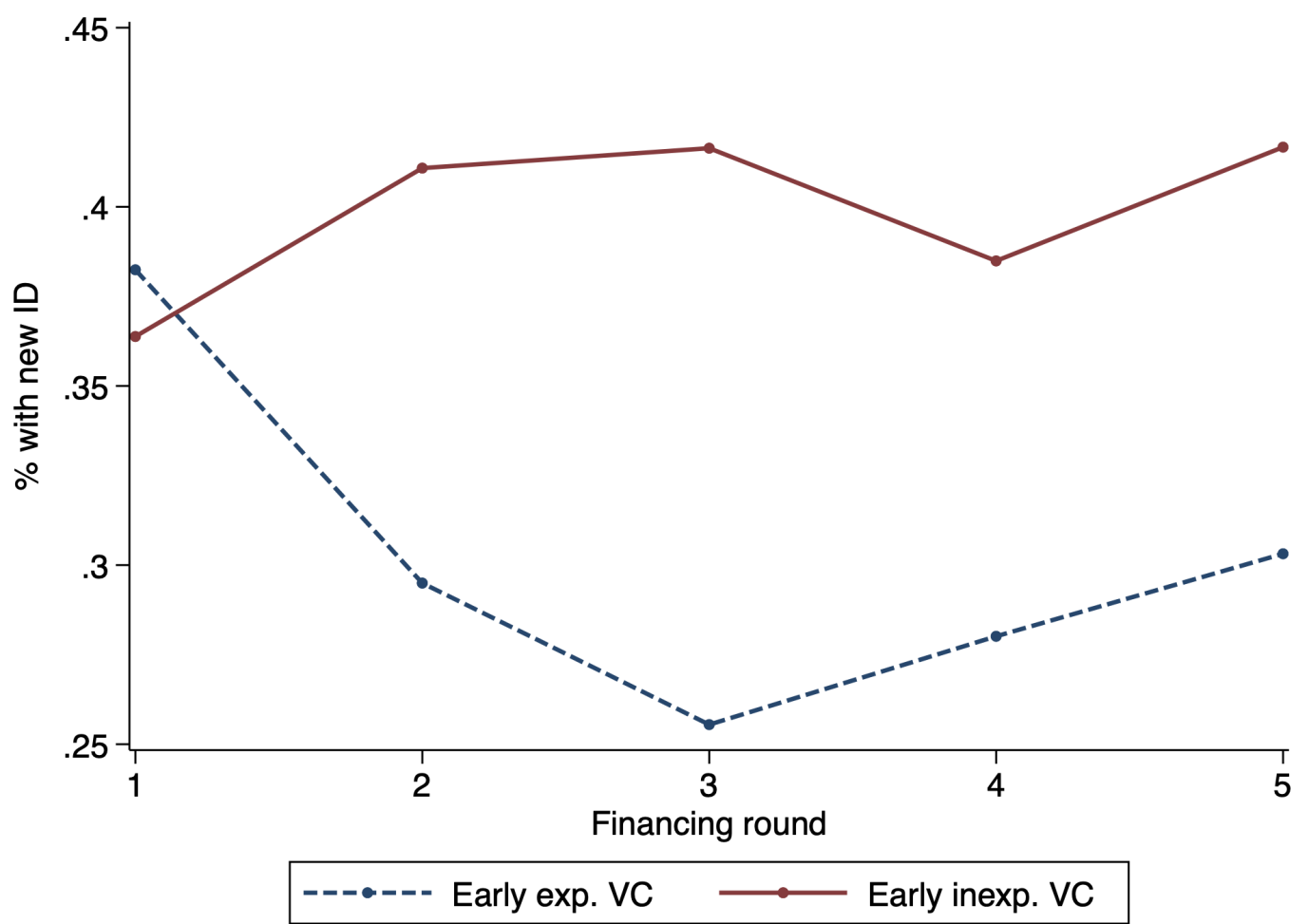


Figure 7: Board composition by exit type

The figure reports average board size, as well as the average fraction of board seats held by executives, independent directors, and investors, for two subsamples: firms that exited via an IPO (right panel) and all others (left panel). The $\mathrm{x}$-axis is the years since the first VC equity financing.
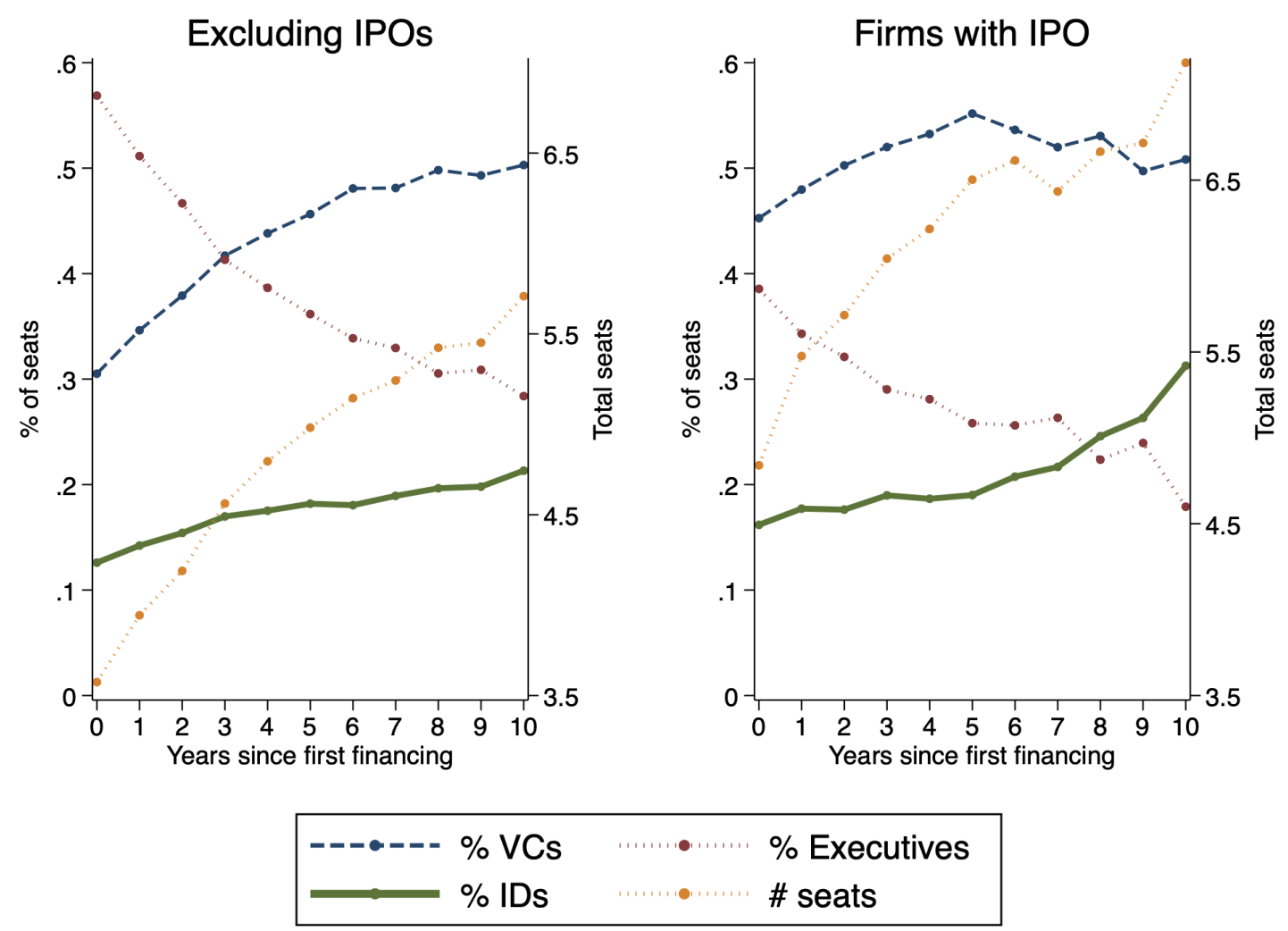


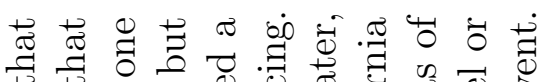

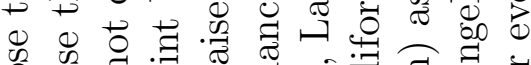

格

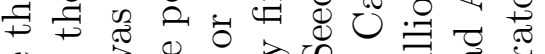

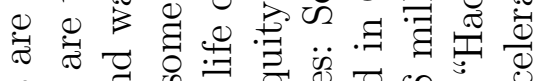

no n

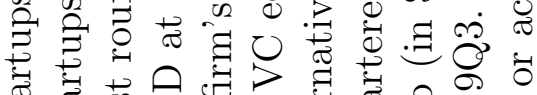

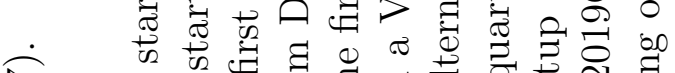

N

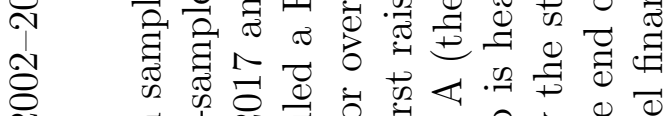

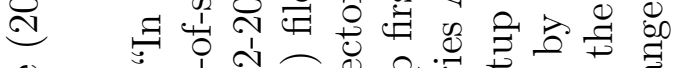

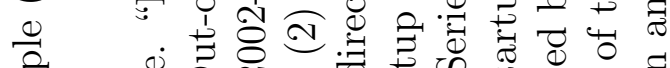

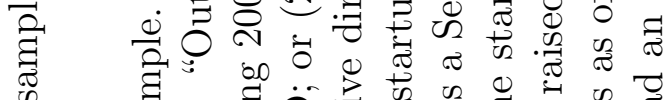

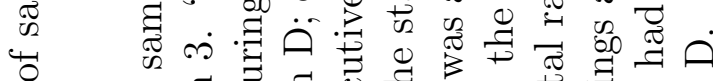

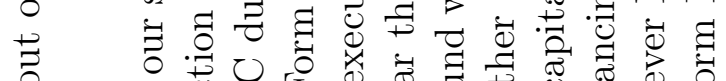

สี

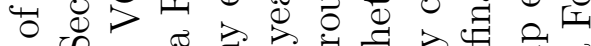
$\exists$ च

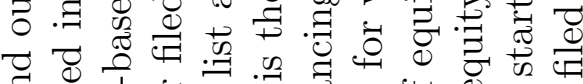

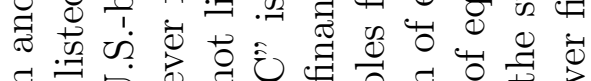
.

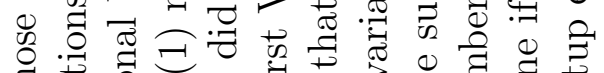

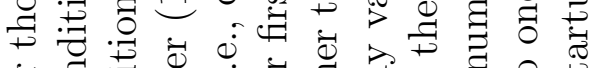

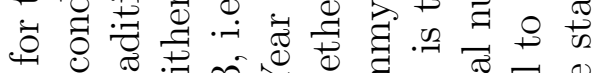

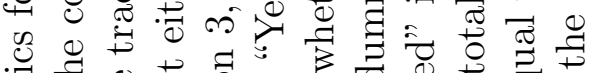

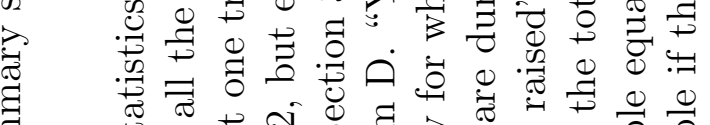
药

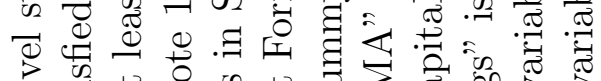

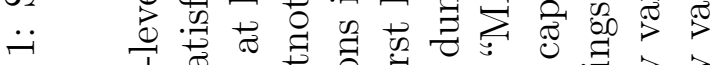

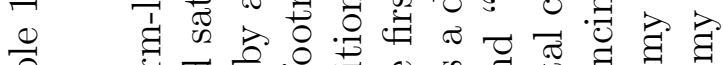

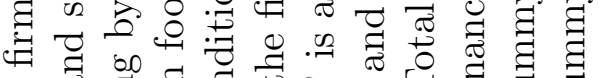

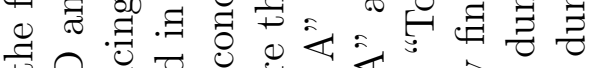

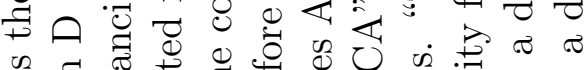

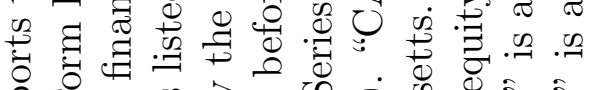

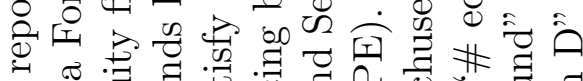

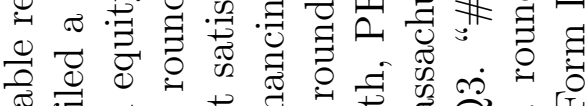
표

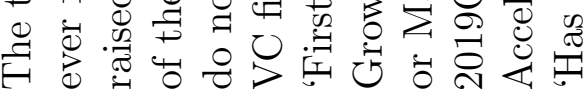

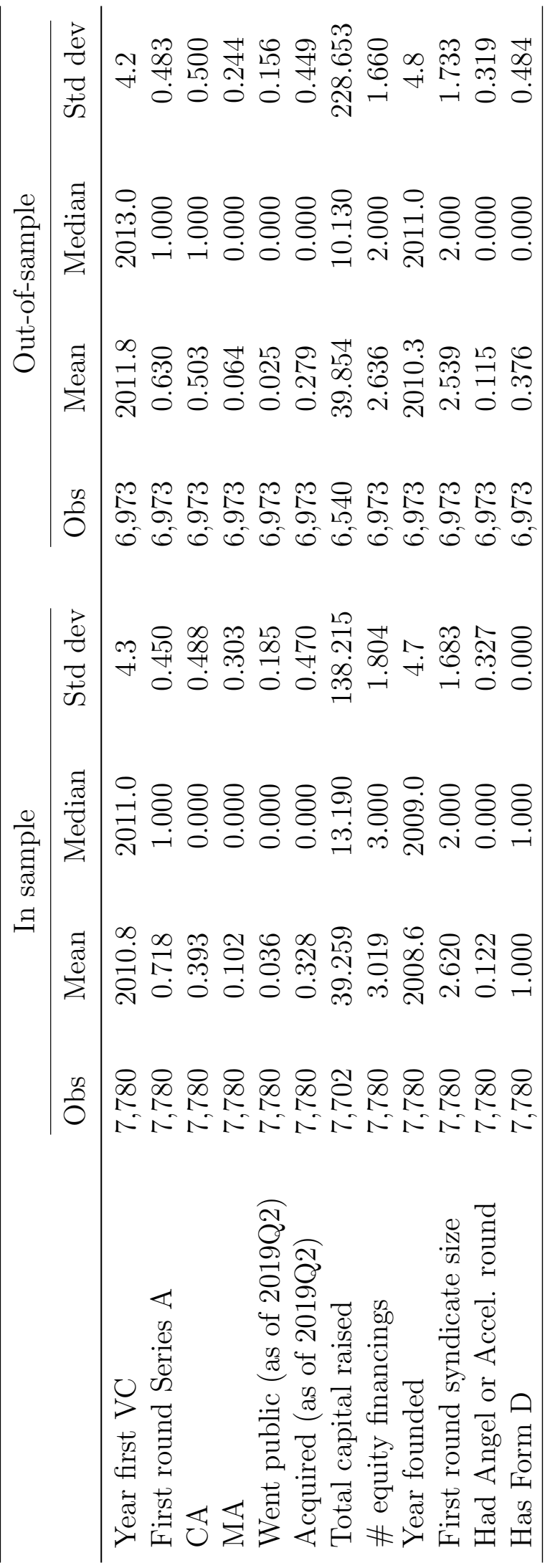




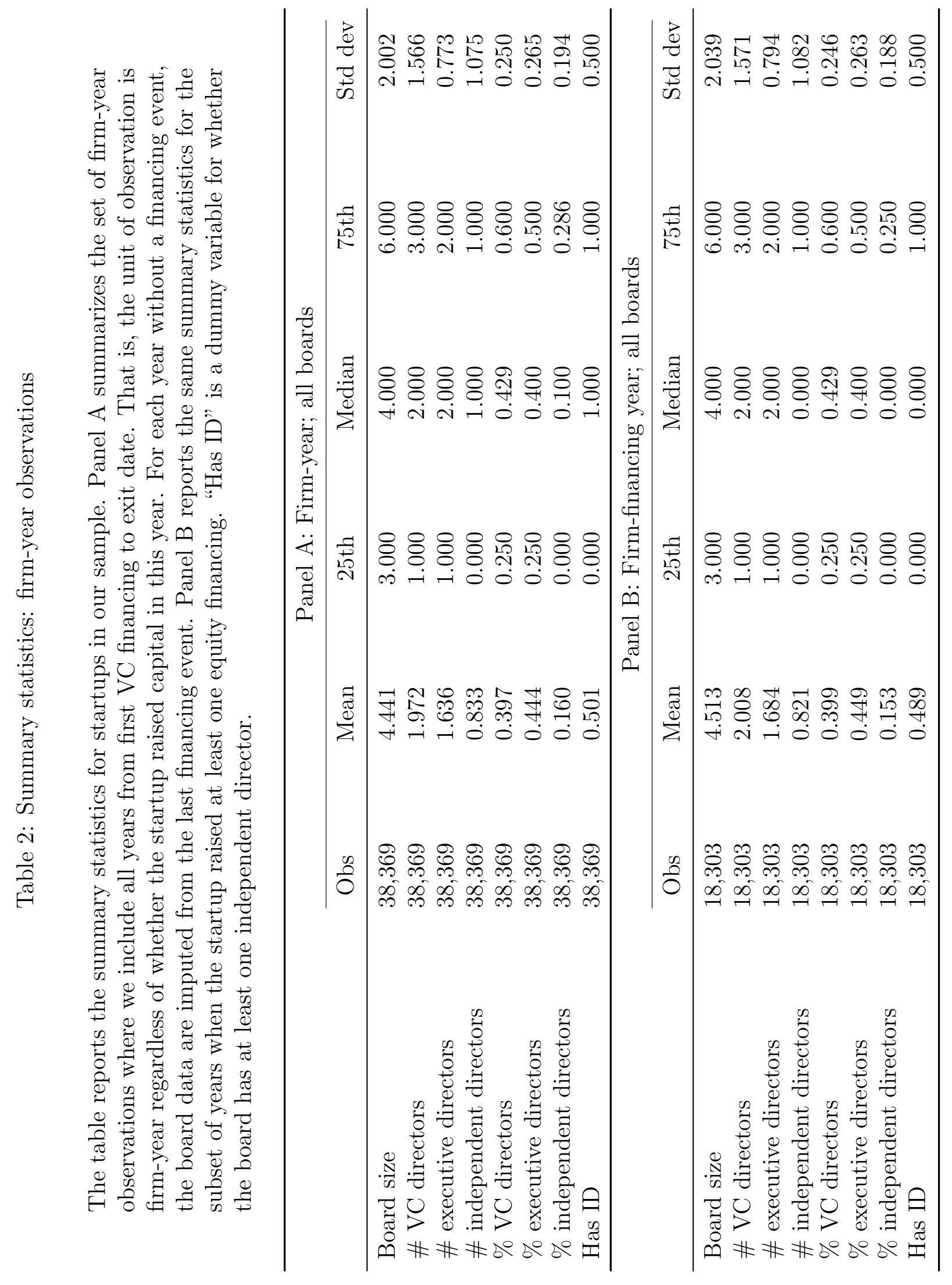




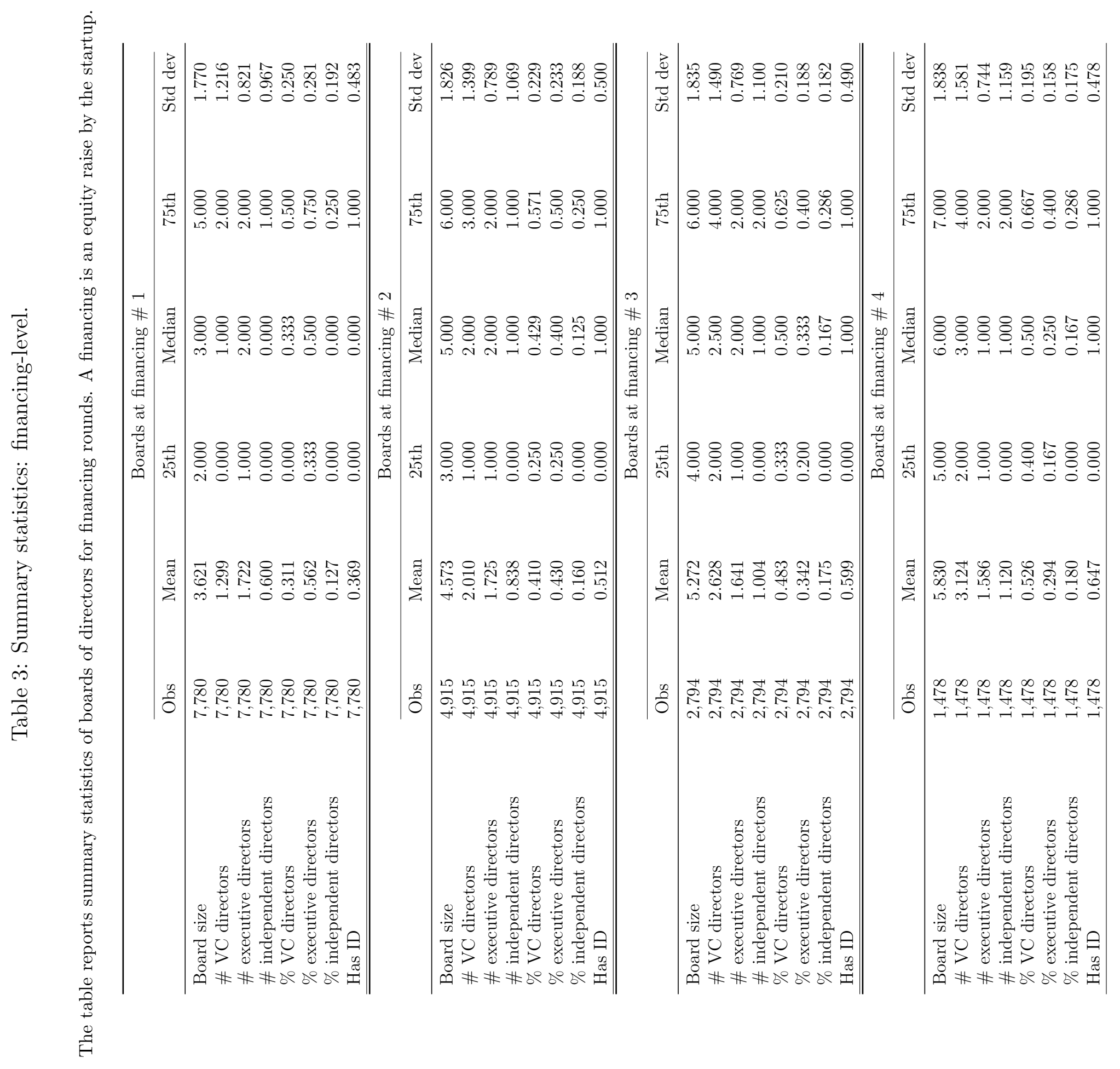


Table 4: Control over the startup life cycle: transition probabilities

The table reports the transition probabilities of board control: conditional on the board having a given allocation of control in one year, it presents the likelihood of any of the three types of allocations of control in the next year. Panel A reports these transition probabilities across all startup financing-years regardless of whether there was a change in board size. Panel B reports these transition probabilities within the subset of financing-years where there is some change in the size of the board.

\begin{tabular}{|c|c|c|c|c|}
\hline & & \multicolumn{3}{|c|}{$\begin{array}{l}\text { Panel A: All financing years } \\
\text { Board control at } t\end{array}$} \\
\hline \multirow{4}{*}{$\begin{array}{c}\text { Board } \\
\text { control } \\
\text { at } t-1\end{array}$} & & $\mathrm{E}$ & Shared & $\mathrm{VC}$ \\
\hline & $\mathrm{E}$ & $55.79 \%$ & $31.36 \%$ & $12.85 \%$ \\
\hline & Shared & $5.41 \%$ & $63.81 \%$ & $30.78 \%$ \\
\hline & $\mathrm{VC}$ & $1.25 \%$ & $10.06 \%$ & $88.68 \%$ \\
\hline & & \multicolumn{3}{|c|}{$\begin{array}{c}\text { Panel B: Years with board size change } \\
\text { Board control at } t\end{array}$} \\
\hline \multirow{4}{*}{$\begin{array}{c}\text { Board } \\
\text { control } \\
\text { at } t-1\end{array}$} & & $\mathrm{E}$ & Shared & $\mathrm{VC}$ \\
\hline & $\mathrm{E}$ & $35.23 \%$ & $46.58 \%$ & $18.20 \%$ \\
\hline & Shared & $8.09 \%$ & $45.84 \%$ & $46.08 \%$ \\
\hline & $\mathrm{VC}$ & $1.71 \%$ & $14.77 \%$ & $83.52 \%$ \\
\hline
\end{tabular}




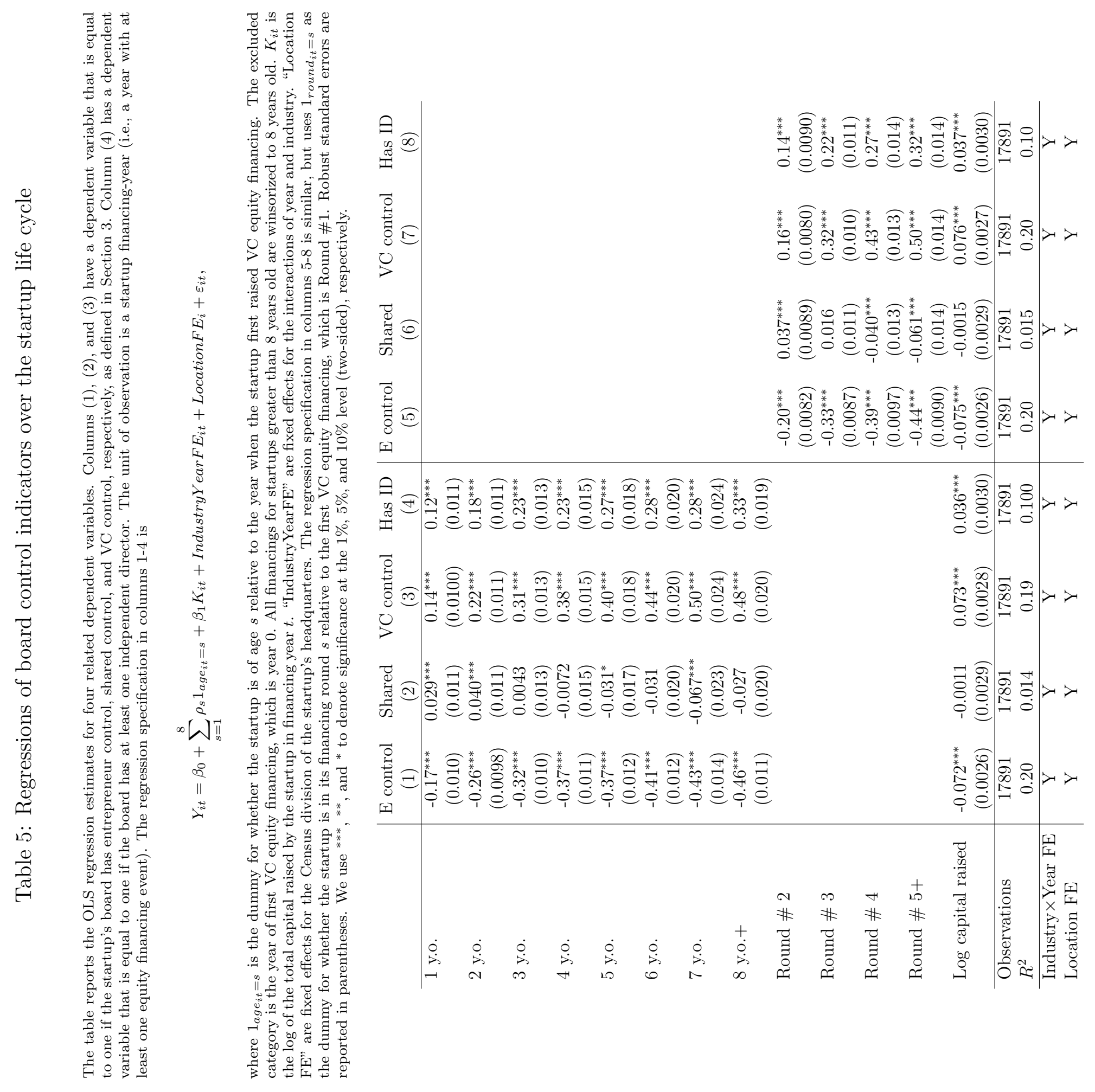




\section{Table 6: Regressions of board characteristics on bargaining power}

The table reports regression analysis of startup boards at their first VC equity financing event. We ask whether the startup board is controlled by the entrepreneur (columns (1) and (5)), whether board control is shared (columns (2) and (6)), whether the board is controlled by the VCs (columns (3) and (7)), and whether the board has at least one independent director (columns (4) and (8)). In Panel A, the main controls are proxies for $\mathrm{VC}$ bargaining power measured at the year prior to the financing round using average equity stakes acquired by VCs in the industry-year (e.g., a VC investment resulted in the sale of $30 \%$ of the as-if-converted shares) and the log of capital raised in the financing round. "Low VC b.p" is equal to one if the startup raised capital after a year of bottom quartile $\mathrm{VC}$ equity stakes in startups in the same industry across the sample period. "High VC b.p." is a dummy for the top quartile (the excluded category is the middle 50\%) of VC equity stakes. Columns (5) - (8) further split the sample periods into quintiles of the bargaining power proxy with the excluded category being the middle quintile. Panel B considers an alternative proxy for bargaining power using the total capital raised by VCs in the region from 1990 up to the previous year net of the total capital invested in startups located in that region from 1996 up to that same previous year. This "dry powder" measure captures the amount of capital available to startups. A region is one of the nine Census divisions of the U.S. Both panels A and B include industry and location fixed effects. Because the measures are within industry or region, the variation within is coming entirely from year of first financing, so the analysis excludes year fixed effects. Robust standard errors are reported in parentheses. We use $^{* * *},{ }^{* *}$, and ${ }^{*}$ to denote significance at the $1 \%, 5 \%$, and $10 \%$ level (two-sided), respectively.

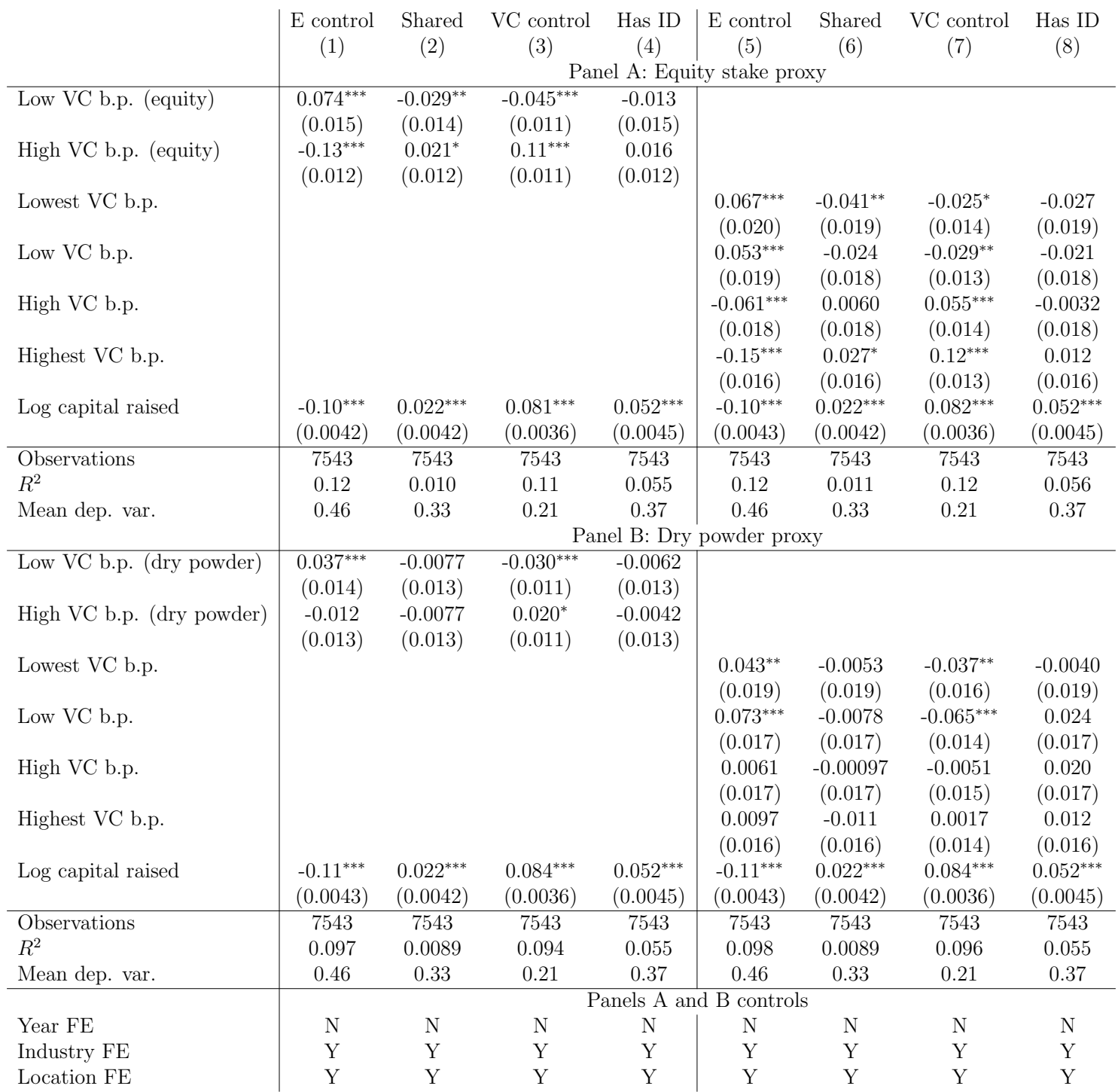




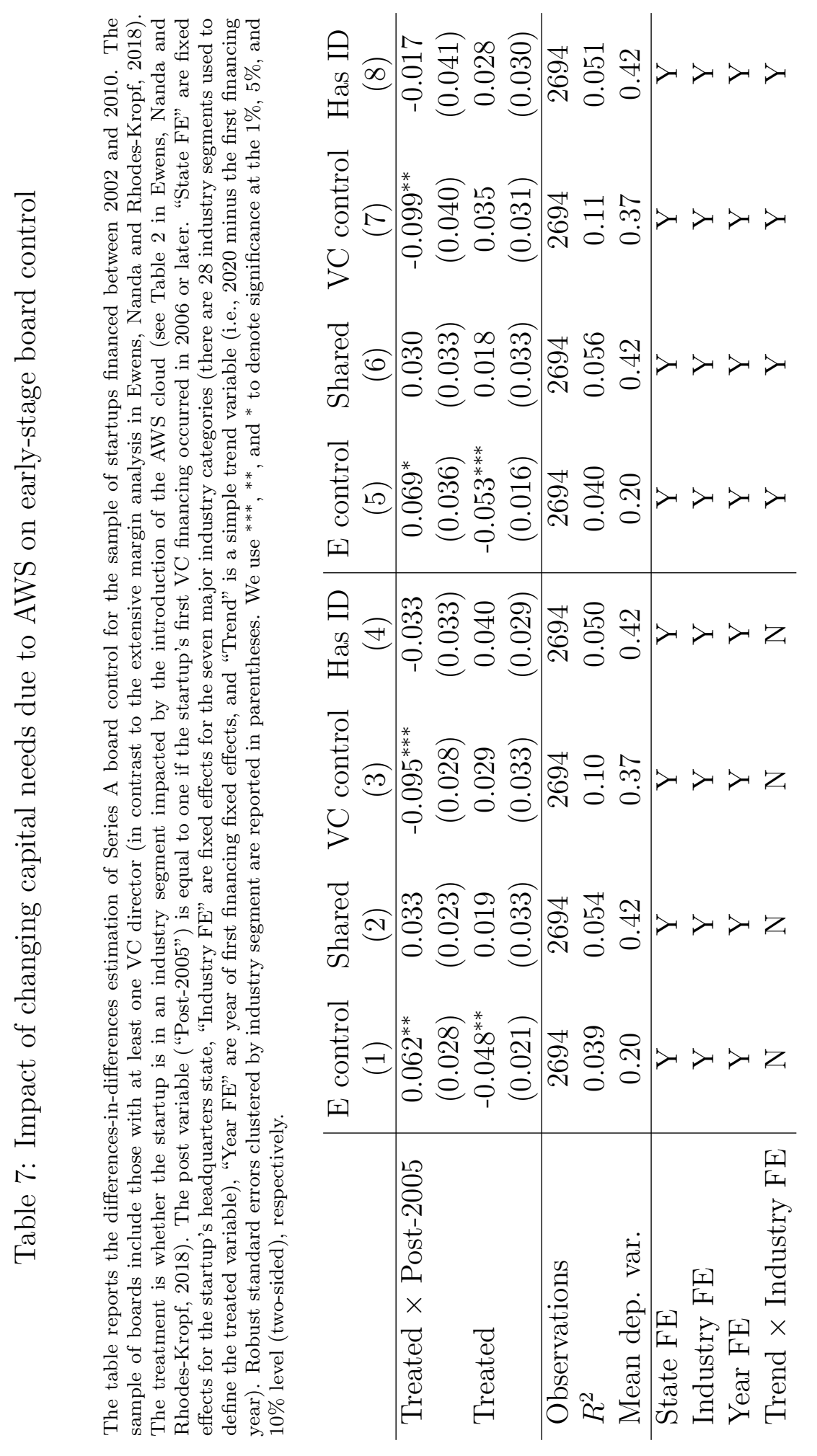




\section{Table 8: Ex-ante conflicts and independent directors in early-stage financings}

The table reports regression analysis of startup boards at their first equity financing event. "Has ID" is an indicator variable equal to one if the board in the first financing round has an independent director. "Shared with ID" is an indicator variable equal to one if the board in the first financing round has shared control with an independent director as a tie-breaker (i.e., it equals to one for all boards with shared control except deadlock boards, as defined in footnote 17). "Has top CEO replacer" is an indicator variable equal to one if at least one of the investors in that financing is identified as a "top CEO replacer," where a "top CEO replacer" in a given quarter-year is a $\mathrm{VC}$ who is in the top quartile of all VCs based on the following variable: the number of CEOs replaced in firms in the VC's portfolio up to that quarter-year divided by the overall number of firms in the VC's portfolio up to that quarter-year. "VC-founder/CEO past interaction" is an indicator equal to one if one of the VCs has a prior investment relationship with either the founder or the first CEO of the startup, in the sense that the VC has in the past invested in another startup where the executive was either the founder of first CEO. "Log VC experience (startups)" is the log of the number of startups invested in by all the investors in the focal financing prior to the focal investment. "Has past founder" is an indicator equal to one if one of the founders of the firm was the founder of a VC-backed startup in the past. "Has past CEO" is an indicator equal to one if the firm's current CEO was the first CEO of a VC-backed startup in the past. Robust standard errors are reported in parentheses. We use ${ }^{* * *},{ }^{* *}$, and ${ }^{*}$ to denote significance at the $1 \%, 5 \%$, and $10 \%$ level (two-sided), respectively.

\begin{tabular}{|c|c|c|c|c|c|c|c|c|}
\hline & \multicolumn{2}{|c|}{ Has ID } & \multicolumn{2}{|c|}{ Shared with ID } & \multicolumn{2}{|c|}{ Has ID } & \multicolumn{2}{|c|}{ Shared with ID } \\
\hline & (1) & $(2)$ & $(3)$ & (4) & (5) & (6) & $(7)$ & (8) \\
\hline Has top CEO replacer & $\begin{array}{c}0.075^{* * *} \\
(0.014)\end{array}$ & $\begin{array}{c}0.070^{* * *} \\
(0.014)\end{array}$ & $\begin{array}{c}0.034^{* * *} \\
(0.012)\end{array}$ & $\begin{array}{l}0.028^{* *} \\
(0.012)\end{array}$ & & & & \\
\hline VC-founder/CEO past interaction & & & & & $\begin{array}{l}0.00097 \\
(0.022)\end{array}$ & $\begin{array}{c}0.011 \\
(0.022)\end{array}$ & $\begin{array}{c}-0.042^{* *} \\
(0.017)\end{array}$ & $\begin{array}{c}-0.034^{* *} \\
(0.017)\end{array}$ \\
\hline Log VC experience (startups) & & $\begin{array}{c}-0.019^{* * *} \\
(0.0042)\end{array}$ & & $\begin{array}{c}-0.019^{* * *} \\
(0.0034)\end{array}$ & & $\begin{array}{c}-0.021^{* * *} \\
(0.0043)\end{array}$ & & $\begin{array}{r}-0.018^{* * *} \\
(0.0034)\end{array}$ \\
\hline Has past founder & & & & & $\begin{array}{l}-0.013 \\
(0.017)\end{array}$ & $\begin{array}{c}-0.0099 \\
(0.017)\end{array}$ & $\begin{array}{r}-0.0061 \\
(0.013)\end{array}$ & $\begin{array}{c}-0.0036 \\
(0.013)\end{array}$ \\
\hline Has past $\mathrm{CEO}$ & & & & & $\begin{array}{c}0.030 \\
(0.029)\end{array}$ & $\begin{array}{c}0.032 \\
(0.029)\end{array}$ & $\begin{array}{r}-0.0011 \\
(0.023)\end{array}$ & $\begin{array}{c}0.00030 \\
(0.023)\end{array}$ \\
\hline Observations & 7779 & 7779 & 7779 & 7779 & 7779 & 7779 & 7779 & 7779 \\
\hline$R^{2}$ & 0.049 & 0.052 & 0.024 & 0.028 & 0.045 & 0.049 & 0.024 & 0.028 \\
\hline Mean dep. var. & 0.37 & 0.37 & 0.18 & 0.18 & 0.37 & 0.37 & 0.18 & 0.18 \\
\hline Year FE & $\mathrm{Y}$ & $\mathrm{Y}$ & $\mathrm{Y}$ & $\mathrm{Y}$ & $\mathrm{Y}$ & $\mathrm{Y}$ & $\mathrm{Y}$ & $\mathrm{Y}$ \\
\hline Industry FE & Y & Y & Y & $\mathrm{Y}$ & Y & Y & Y & Y \\
\hline State FE & Y & Y & Y & Y & Y & $\mathrm{Y}$ & Y & Y \\
\hline
\end{tabular}




\section{Table 9: Summary statistics: Independent director characteristics}

The table reports the descriptive statistics for the independent directors (IDs) in our sample. "ID is in VentureSource" is a dummy for whether the ID is found in VentureSource. For those directors in VentureSource for which a biographical string is available, \# job titles (in bio.); \# CEO positions (in bio.); \# C-level (in bio.); and \# VP-level (in bio.) are, respectively, the number of past jobs listed in the biography; the number of CEO titles listed in the biography; the number of C-level positions listed in the biography; and the number of past VP-level positions listed in the biography, all measured at the time when the ID joins his last board seat in our sample. "Past founder" is a dummy for whether the ID is found as a former founder based on the biographical string or in VentureSource overall. "Total board seats" is the total number of board seats as a VC-director or ID over the director's career in our sample. "Sat on public board" is a dummy equal to one if the director has been found in BoardEx in a director position on a public firm. "Avg. age startup at join (yrs.)" and "Avg. tenure at startup (yrs.)" are, respectively, the average age of the firm when the ID joins the board and the average number of years spent on the board, averaged across all boards of the ID in our sample.

\begin{tabular}{lcccccc}
\hline & \multicolumn{5}{c}{ Independent director characteristics } \\
\cline { 2 - 7 } & Obs & Mean & 25th & Median & 75 th & Std dev \\
\hline ID is in VentureSource & 8,038 & 0.814 & 1.000 & 1.000 & 1.000 & 0.390 \\
\# job titles (in bio.) & 4,619 & 3.418 & 2.000 & 3.000 & 5.000 & 2.462 \\
\# CEO positions (in bio.) & 4,619 & 0.626 & 0.000 & 0.000 & 1.000 & 1.027 \\
\# C-level (in bio.) & 4,619 & 1.246 & 0.000 & 1.000 & 2.000 & 1.516 \\
\# VP-level (in bio.) & 4,619 & 0.606 & 0.000 & 0.000 & 1.000 & 0.955 \\
Past founder & 4,644 & 0.250 & 0.000 & 0.000 & 0.000 & 0.433 \\
Total board seats & 8,038 & 1.159 & 1.000 & 1.000 & 1.000 & 0.524 \\
Sat on public board & 8,038 & 0.085 & 0.000 & 0.000 & 0.000 & 0.280 \\
Avg. age startup at join (yrs.) & 8,038 & 2.024 & 0.000 & 1.129 & 3.146 & 2.516 \\
Avg. tenure at startup (yrs.) & 8,038 & 3.267 & 1.000 & 2.000 & 5.000 & 2.781 \\
Female & 7,706 & 0.082 & 0.000 & 0.000 & 0.000 & 0.275 \\
\hline
\end{tabular}




\section{Table 10: Mediation and advisory roles over the life cycle}

The table reports the regression estimates of the stage when an independent director joins the board on director characteristics. A unit of observation is a financing-year when a new independent director joins the board. The left-hand side variable in Panel A is a dummy "joined a late-stage board", which equals one if the independent director joined the board at least five years following the first VC financing. The left-hand side variable in Panel B is a dummy for "joined board at shared or E-control", which equals one if the independent director joined the board in the year when the board had either shared or entrepreneur control (i.e., not VC control). "Past founder", "Unconnected", and "Sat on public board" are dummy variables, while other right-hand side variables are log one plus the variable. "Unconnected" is defined in Section A4 of the Internet Appendix, and the definitions of the other right-hand side variables are given in the captions to Table 9. All the variables are at the director-firm level and measure the director's experience prior to joining the focal board. "Firm age FE (year)" are the fixed effects for the firm's age measured in years. Robust standard errors are reported in parentheses. We use ${ }^{* * *},{ }^{* *}$, and ${ }^{*}$ to denote significance at the $1 \%, 5 \%$, and $10 \%$ level (two-sided), respectively.

\begin{tabular}{|c|c|c|c|c|c|}
\hline & \multicolumn{4}{|c|}{ Panel A: Joined a late-stage board } & (5) \\
\hline Past founder & $\begin{array}{c}-0.064^{* * *} \\
(0.0090)\end{array}$ & & & & \\
\hline Unconnected & & $\begin{array}{c}0.0033 \\
(0.0093)\end{array}$ & & & \\
\hline Log \# C-level & & & $\begin{array}{l}0.027^{* * *} \\
(0.0093)\end{array}$ & & \\
\hline Log \# VP-level & & & & $\begin{array}{c}0.036^{* * *} \\
(0.011)\end{array}$ & \\
\hline Sat on public board & & & & & $\begin{array}{c}0.095^{* * *} \\
(0.017)\end{array}$ \\
\hline Log \# job titles & $\begin{array}{c}0.015^{*} \\
(0.0081)\end{array}$ & $\begin{array}{c}0.0029 \\
(0.0082)\end{array}$ & $\begin{array}{c}-0.017^{*} \\
(0.010) \\
\end{array}$ & $\begin{array}{c}-0.013 \\
(0.0087)\end{array}$ & $\begin{array}{c}-0.0023 \\
(0.0079)\end{array}$ \\
\hline Observations & 5108 & 5108 & 5108 & 5108 & 5108 \\
\hline$R^{2}$ & 0.081 & 0.074 & 0.075 & 0.076 & 0.083 \\
\hline Mean dep. var. & 0.12 & 0.12 & 0.12 & 0.12 & 0.12 \\
\hline Year FE & $\bar{Y}$ & $\bar{Y}$ & $\mathrm{Y}$ & $\bar{Y}$ & $\mathrm{Y}$ \\
\hline Industry FE & Y & Y & Y & $\mathrm{Y}$ & Y \\
\hline & $\begin{array}{l}\text { Panel } \\
\text { (1) }\end{array}$ & $\begin{array}{l}\text { 3: Joined } \\
\text { (2) }\end{array}$ & $\begin{array}{l}\text { oard at s } \\
\text { (3) }\end{array}$ & $\begin{array}{c}\text { ared or } \mathrm{E}- \\
\text { (4) }\end{array}$ & $\begin{array}{r}\text { control } \\
(5)\end{array}$ \\
\hline Past founder & $\begin{array}{l}0.023^{*} \\
(0.014)\end{array}$ & & & & \\
\hline Unconnected & & $\begin{array}{c}0.058^{* * *} \\
(0.013)\end{array}$ & & & \\
\hline Log \# C-level & & & $\begin{array}{c}-0.033^{* *} \\
(0.013)\end{array}$ & & \\
\hline Log \# VP-level & & & & $\begin{array}{c}-0.054^{* * *} \\
(0.014)\end{array}$ & \\
\hline Sat on public board & & & & & $\begin{array}{c}-0.054^{* * *} \\
(0.020)\end{array}$ \\
\hline Log \# job titles & $\begin{array}{c}-0.038^{* * *} \\
(0.012)\end{array}$ & $\begin{array}{l}-0.019 \\
(0.012)\end{array}$ & $\begin{array}{l}-0.010 \\
(0.015)\end{array}$ & $\begin{array}{l}-0.011 \\
(0.013)\end{array}$ & $\begin{array}{c}-0.031^{* * *} \\
(0.012)\end{array}$ \\
\hline Observations & 5108 & 5108 & 5108 & 5108 & 5108 \\
\hline$R^{2}$ & 0.072 & 0.076 & 0.073 & 0.074 & 0.073 \\
\hline Mean dep. var. & 0.73 & 0.73 & 0.73 & 0.73 & 0.73 \\
\hline Year $\mathrm{F}$ & $\mathrm{Y}$ & $\bar{Y}$ & $\mathrm{Y}$ & $\mathrm{Y}$ & $\mathrm{Y}$ \\
\hline Industry & Y & Y & Y & Y & Y \\
\hline Firm age FE (year) & Y & $\mathrm{Y}$ & $\mathrm{Y}$ & Y & Y \\
\hline
\end{tabular}


Table 11: Control over the life cycle and bargaining power predictions (with connections)

Panel A of this table is the analog of Table 5, but using the data on director connections to redefine board control. Panels B and C are the analog of Table 6, but using the data on director connections to redefine board control. "Has unc. ID" is a dummy for the presence of an unconnected independent director. All other variables are as defined in Table 5. "Controls" in Panels B and C is the log of capital raised in the financing round. Robust standard errors reported in parentheses. We use ${ }^{* * *},{ }^{* *}$, and ${ }^{*}$ to denote significance at the $1 \%, 5 \%$, and $10 \%$ level (two-sided), respectively.

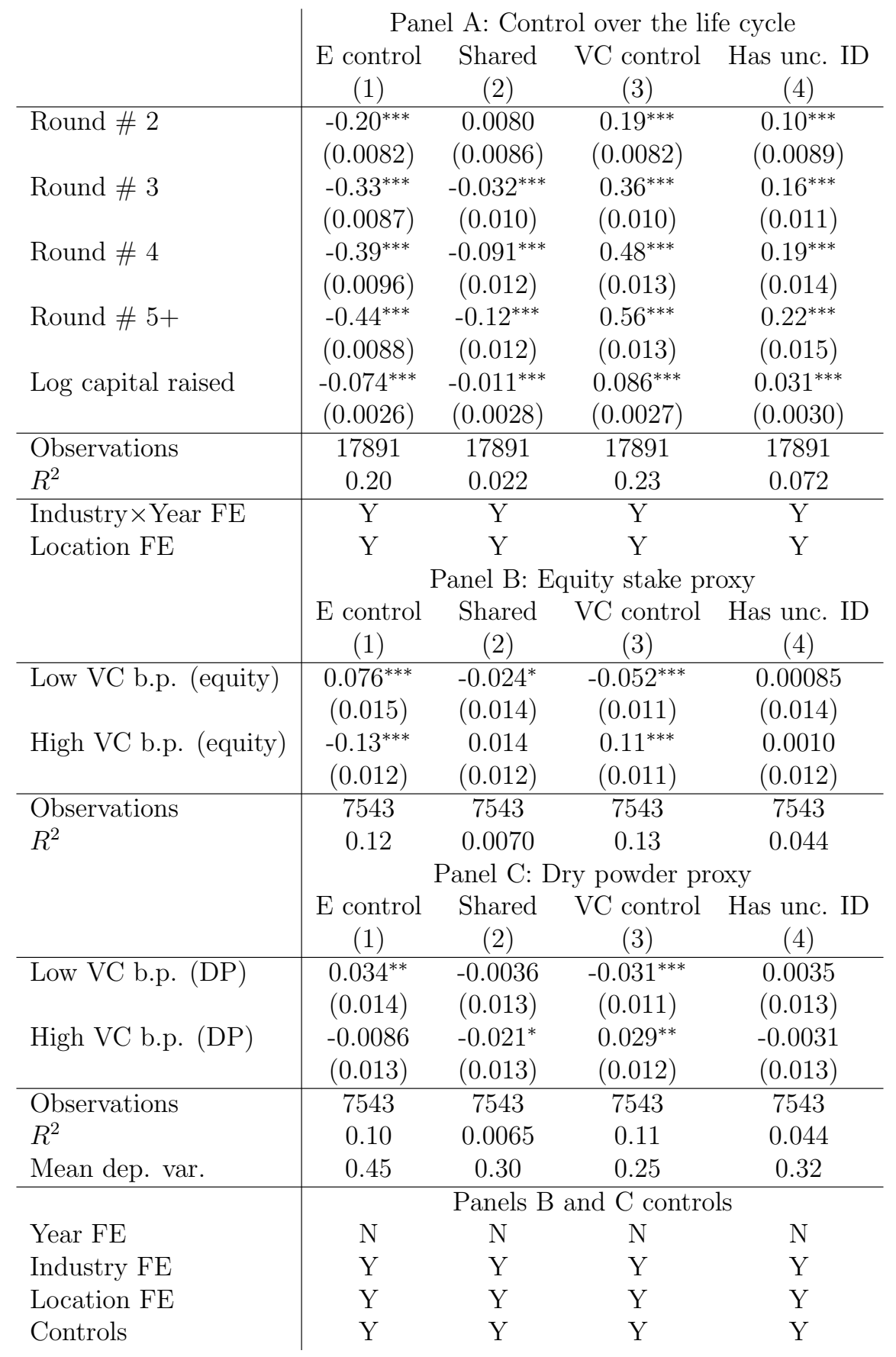

